\title{
The Axial Ligation and Stoichiometry of Heme Centers in Adrenal Cytochrome $b_{561}{ }^{\dagger}$
}

\author{
Yury Kamensky ${ }^{\ddagger}{ }^{*}$, Wen Liull, Ah-Lim Tsail , Richard J. Kulmacz" , and Graham Palmer ${ }^{\ddagger},{ }^{*}$ \\ \$Department of Biochemistry and Cell Biology, Rice University, Houston, TX 77251, USA \\ IDepartment of Internal Medicine, University of Texas Health Science Center at Houston, Houston, TX 77030, \\ USA
}

\begin{abstract}
Cytochrome (cyt) $b_{561}$ transports electrons across the membrane of chromaffin granules (CG) present in the adrenal medulla, supporting the biosynthesis of norepinephrine in the CG matrix. We have conducted a detailed characterization of cyt $b_{561}$ using electron paramagnetic resonance (EPR) and optical spectroscopy on the wild type and mutant forms of the cytochrome expressed in insect cells. The $g_{\mathrm{z}}=3.7$ (low-potential heme) and $\mathrm{g}_{\mathrm{z}}=3.1$ (high-potential heme) signals were found to represent the only two authentic hemes of cyt $b_{561}$; models that propose smaller or greater amounts of heme can be ruled out. We identified the axial ligands to hemes in cyt $b_{561}$ by mutating four conserved histidines (His54 and His122 at the matrix-side heme center and His 88 and His 161 at the cytoplasmicside heme center), thus confirming earlier structural models. Single mutations of any of these histidines produced a constellation of spectroscopic changes that involve not one but both heme centers. We hypothesize that the two hemes and their axial ligands in cyt $b_{561}$ are integral parts of a structural unit that we term the "kernel". Histidine to glutamine substitutions in the cytoplasmic-side heme center, but not in the matrix-side heme center, led to the retention of a small fraction of the low-potential heme with $g_{z}=3.7$. We provisionally assign the low-potential heme to the matrix side of the membrane; this arrangement suggests that the membrane potential modulates electron transport across the CG membrane.
\end{abstract}

Most, if not all, eukaryotic organisms carry a gene for at least one member of the newly discovered protein family of cytochrome $b_{561}\left(\mathrm{cyt} b_{561}\right)^{1}(1-4)$. The oldest known member of the family, adrenal-type cyt $b_{561}$, is essentially an ascorbate-regeneration machine (5) that plays a key role in supplying electrons for the biosynthesis of norepinephrine by dopamine- $\beta$ hydroxylase (6) and of several important peptide hormones by peptidylglycine $\beta$ monooxygenase (6). Several other cyt $b_{561}$ family members are either suggested to participate in ascorbate metabolism or to depend on ascorbate for ferric-reductase activity. Among them

\footnotetext{
${ }^{\dagger}$ This work was supported by American Heart Association (Texas Affiliate) Grant 0455107Y (G.P.), National Institutes of Health GM44911 (A-L.T.).

*Address correspondence to these authors: Y. Kamensky, Department of Biochemistry and Cell Biology, Rice University, Houston, TX 77251, USA. Telephone: 713-348-3903. FAX: 713-348-5154. E-mail: yuryk@bioc.rice.edu

G. Palmer, Department of Biochemistry and Cell Biology, Rice University, Houston, TX 77251, USA. Telephone: 713-348-4860. FAX: 713-348-5154. E-mail: graham @bioc.rice.edu.

${ }^{3}$ Our earlier publication (Kamensky, Y.A. and Palmer, G. (2001) Chromaffin granule membranes contain at least three heme centers, FEBS Lett. 491, 119-22) considered a third heme as either a cyt b561 component or another heme-containing protein present in the CG membrane. That this third heme is not a part of cyt $b_{561}$ itself is now confirmed, as neither purified cyt $b_{561}$ from CG nor those expressed in insect, yeast or bacterial cells contain a heme with $\mathrm{g}$ factor of 3.62 that is not reduced by ascorbate. The origin and function of the third heme in CG remain unresolved, although Ponting speculated that it may be the heme of a cyt $b$-type iron reductase (Ponting, C. P. (2001) Domain homologues of dopamine $\beta$-hydroxylase and ferric reductase: roles for iron metabolism in neurodegenerative disorders? Hum. Mol. Genet. 10, 1853-1858).
} 
are: stromal-cell derived receptor 2 , which is an iron reductase expressed in major iron storage organs (7,8); a newly discovered analog with ferric-reductase activity, Lcyt $b_{561}$, which was found in macrophage lysosomes (9); Tcyt $b_{561}$, a cytochrome recently reported as a constituent of tonoplast membrane in Arabidopsis (10); mammalian duodenal $b_{561}$ (Dcyt $b_{561}$ ), which participates in the uptake of dietary iron in the brush border membrane of the duodenum (8, 11) (but see (12,13)), iron uptake in airway epithelial cells (14) and possibly in extracellular ascorbate recycling in human erythrocytes (15). Another interesting member of cyt $b_{561}$ family is the 101F6 protein, a putative tumor suppressor with an unknown mechanism of action (16, 17). Many species have multiple cyt $b_{561}$ family members, with six known in humans and as many as sixteen in Arabidopsis thaliana. Thus, the cyt $b_{561}$ family appears to be important for the biology of eukaryotes (1).

With most of the proteins constituting this family still waiting for physico-chemical characterization, the development of a structural and functional model of a prototypic representative would be valuable as a point of comparison. Adrenal cyt $b_{561}$ is undoubtedly the current best choice for such a prototype because: (a) a significant database already exists for this protein; (b) it is highly abundant, comprising $17 \%$ of the total protein in its natural source, the membrane of chromaffin granules (CG) located in the medulla of adrenal glands (18); and (c) it has been expressed in fully functional form in insect $(19,20)$, yeast $(20,21)$ and recently in bacterial (22) cells.

According to the current paradigm (5), the synthesis of each molecule of norepinephrine by dopamine- $\beta$-hydroxylase within $\mathrm{CG}$ requires two electrons provided by intra-granular ascorbic acid (6). In this process, two ascorbic acid molecules inside the granule undergo one-electron oxidation to monodehydroascorbate (23) and must be replenished. Neither fully reduced

\footnotetext{
${ }^{1}$ Abbreviations:

cyt

cytochrome

CG

chromaffin granules

M

matrix

C

cytoplasmic

MDA

monodehydroascorbate

PAL

putative axial ligand

EPR

electron paramagnetic resonance spectroscopy

HALS

highly axial low spin

ALA

$\delta$-aminolevulinic acid

EDTA

ethylenediamine tetraacetic acid

DM

n-dodecyl- $\beta$-D-maltoside

SVD

singular value decomposition
} 
ascorbate nor matrix monodehydroascorbate can penetrate the granule membrane (24-26), and cyt $b_{561}$ regenerates intra-granular ascorbate by transferring electrons acquired from cytoplasmic ascorbate (5,27-32).

Adrenal cyt $b_{561}$ consists of 252 amino acid residues with an $\mathrm{M}_{\mathrm{r}}$ of $28 \mathrm{kDa}(33,34)$. Sequence analysis of adrenal cyt $b_{561}$ predicts six transmembrane helices (33) with the central four helices forming a bundle (3) carrying the hemes (35). Although all models of cyt $b_{561}$ beginning with that of Degli Esposti et al. (35) consider cyt $b_{561}$ to contain two hemes, the heme stoichiometry has remained an unsettled issue. Based on an apparent heme-to-protein ratio of one, early literature considered cyt $b_{561}$ to contain a single heme (27,36-39). Tsubaki et al. (40) developed a mild purification procedure and reported the isolation from CG of cyt $b_{561}$ containing two hemes. Subsequent expression and purification of a recombinant, his-tagged bovine cyt $b_{561}$ from yeast and insect cells also yielded proteins with two hemes per polypeptide (20). The two hemes were reported to have different low-spin signals in electron paramagnetic resonance (EPR) spectra, with low-field g-values of 3.1 and 3.7 (40-42), though recently Wanduragala et al. (43) raised doubts regarding the authenticity of the $g_{z}=3.7$ signal in their sample of purified cyt $b_{561}$. Kipp et al. (44) suggested that the second EPR signal is not a manifestation of an independent heme center but represents heme-heme interaction between two different mono-heme protein molecules. On the other hand, Burbaev et al. (41) and later Kamensky et al. (19) observed heterogeneity in the EPR signal of one of the hemes and noted the possibility that membranous cyt $b_{561}$ contained 3 hemes (41), perhaps in the framework of a dimeric cyt $b_{561}$ structure (19).

Bis-histidine ligation is very likely for all the heme of cyt $b_{561}(41,45)$. Kamensky et al. (45) observed that cyt $b_{561}$ lacks the characteristic charge transfer band near $700 \mathrm{~nm}$ that is typical for methionine coordination in cytochromes $c$ (46) and in cyt $b_{562}$ from $E$. coli (47). In addition, the marked similarity of the magnetic circular dichroism in the beta-band of reduced cyt $b_{561}$ with that of cyt $b_{5}(45)$ and the bis-imidazole complex of protoheme makes coordination by lysine unlikely (48), leaving the imidazole side-chain of histidines as the most credible candidates for axial ligands to heme in cyt $b_{561}$ (45). The EPR spectral characteristics of cyt $b_{561}(20,21,40-42)$ are consistent with histidine axial ligands, as are the near-IR magnetic circular dichroism spectra of cyt $b_{561}$ (E. Duin, Y. Kamensky, M. Johnson, G. Palmer, unpublished).

Six fully conserved histidines (His54, His88, His92, His110, His122 and His161 in adrenal cyt $b_{561}$ ) have been identified in cyt $b_{561}$ from different species (1). Degli Esposti et al. (35), and later other investigators (1-3,49), suggested that His54 and His122 are the axial ligands to the heme on the matrix (M) side of the CG membrane, and that His88 and His161 provide axial ligation to the heme on the cytoplasmic (C) side. However, this hypothesis has been waiting for experimental confirmation. An important step in this direction was recently taken by Bérczi et al. (21). Their results suggested that His 110 could be excluded from the list of potential axial ligands to heme and were consistent with the idea of His88, His161, His54 and His122 being the axial ligands. In the absence of an X-ray structure, the assignment of individual axial ligands to a particular heme center can be examined by EPR analysis of recombinant cyt $b_{561}$ in which putative axial ligands (PALs) are replaced systematically by mutagenesis. EPR is very sensitive to the properties and environment of the oxidized (paramagnetic) heme centers of cytochromes (50) and, importantly, the two heme EPR signals in cyt $b_{561}$ are well resolved (40-42).

We present here a comparative EPR and optical study of natural and recombinant wild type cyt $b_{561}$, as well as mutants of bovine adrenal cytochrome, with the goal of resolving remaining questions regarding the fundamental characterization of cyt $b_{561}$, namely the quantity of its hemes and identification of their axial ligands. 


\section{EXPERIMENTAL PROCEDURES}

\section{Materials}

Hemin, DTT, EDTA, cholate, desoxycholate, ALA, and horse heart cytochrome $c$ were from Sigma (St. Louis, MO). Frozen bovine adrenal glands were purchased from Pel-Freez (Rogers, AR), while fresh glands were obtained from a slaughterhouse. Protease inhibitor cocktail Set 1 and Set III (without EDTA) were from Calbiochem (San Diego, CA). Ascorbic acid sodium salt and sodium dithionite were obtained from Fluka (Germany). n-Octyl- $\beta$ - - -glucoside and ndodecyl- $\beta$-D-maltoside, CHAPS, PMAL-c12, Triton X-100 were from Anatrace (Maumee, $\mathrm{OH})$.

\section{CG and CG membrane vesicles preparation}

Fresh and pre-frozen adrenal glands were used for preparation of CG and different types of membrane vesicles as described previously $(20,42)$.

\section{Cyt $b_{561}$ from CG}

Purification of cyt $b_{561}$ from natural membranes was performed according to the protocol developed by Tsubaki et al. (40)

\section{Recombinant bovine cyt $b_{561}$}

Expression of his-tagged bovine cyt $b_{561}$ in $S f 9$ insect cells and purification of membranous and isolated recombinant protein were performed as described previously (20). The membranous preparations of mutated cyt $b_{561}$ were prepared by the method developed in (20) for the wild type, where the membranes were collected at 150,000 g with or without prior removal of the $500 \mathrm{~g}$ and $15,000 \mathrm{~g}$ fractions. Site-directed mutagenesis of bovine cyt $b_{561}$ was performed on the b561/pBluescript II KS (+) plasmid using QuikChange site-directed mutagenesis kit (Stratagene). The primer sequences containing the mutation (the bases changed are underlined) were:

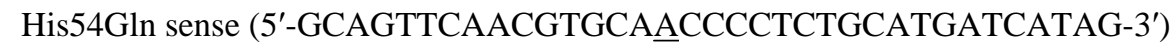

His54Gln antisense (5'-CTATGATCATGCAGAGGGGTTGCACGTTGAACTGC-3')

His54Met sense (5'-CTGCAGTTCAACGTGATGCCCCTCTGCATGATC-3')

His54Met antisense (5'-GATCATGCAGAGGGGCATCACGTTGAACTGCAG-3')

His54Tyr sense (5'-CTGCAGTTCAACGTGTACCCCCTCTGCATGATC-3')

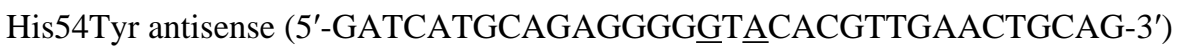

His88Gln sense (5'-ACCAAAGTCCTGCAAGGGCTGCTGCACGTCTTC-3')

His88Gln antisense (5'-GAAGACGTGCAGCAGCCCTTGCAGGACTTTGGT-3')

His122Gln sense (5'-ACCTGTACAGCCTGCAAAGCTGGTGCGGCATCC-3')

His122Gln antisense (5'-GGATGCCGCACCAGCTTTGCAGGCTGTACAGGT-3')

His161Gln sense (5'-GCTACCGCCCGCAGCAAGGTCTTCTTCGGCG-3')

His161Gln antisense (5'-CGCCGAAGAAGACTTGCTGCGGGCGGTAGC-3')

His161Met sense (5'-CGCTACCGCCCGCAGATGGTCTTCTTCCGGCGC-3')

His161Met antisense (5'-GCGCCGAAGAAGACCATCTGCGGGCGGTAGCG-3')

His161Tyr sense (5'-CGCTACCGCCCGCAGTACGTCTTCTTCGGCG-3') 


\section{His161Tyr antisense (5'-CGCCGAAGAAGACGTACTGCGGGCGGTAGCG-3')}

E. coli strain XL-10 (Stratagene) competent cells were heat transformed with the mutagenesis reaction, plated on LB agar containing $100 \mu \mathrm{g} / \mathrm{ml}$ ampicillin, and grown overnight. Ampicillinresistant colonies were grown in LB-ampicillin broth at $37^{\circ} \mathrm{C}$ overnight, and plasmid DNA was isolated. Clones were screened for the presence of the desired mutation by DNA sequencing, digested with $\mathrm{BamHI} / \mathrm{XbaI}$ and separated on an agarose gel. The purified $b_{561}$ fragments containing the desired mutations were inserted into BamHI/XbaI digested pVL1393 vector (PharMingen, San Diego, CA). The final constructs were verified by restriction enzyme digestion and DNA sequencing. Construction of baculoviral vectors for expression of mutant cyt $b_{561}$ in insect cells followed published procedures (51).

\section{Assay of protein, cyt $b_{561}$ and heme content}

Total protein was assayed with a BioRad DC kit, using bovine albumin as the standard. Recombinant cyt $b_{561}$ content was calculated using a difference extinction coefficient of 34 $\mathrm{mM}^{-1} \mathrm{~cm}^{-1}(561 \mathrm{~nm}-575 \mathrm{~nm}$, reduced minus oxidized spectrum (20)). The concentration of membranous and purified CG cyt $b_{561}$ was calculated using a difference extinction coefficient $37.3 \mathrm{mM}^{-1} \mathrm{~cm}^{-1}(561 \mathrm{~nm}-575 \mathrm{~nm}$, reduced minus oxidized spectrum (40)). Heme content was determined by the pyridine hemochrome assay (52), using a difference extinction coefficient $(556 \mathrm{~nm}-538 \mathrm{~nm})$ of $24.5 \mathrm{mM}^{-1} \mathrm{~cm}^{-1}(53)$.

\section{EPR sample preparation}

Samples were oxidized with an excess of ferricyanide. Membranous samples were then washed twice by centrifugation ( $1 \mathrm{~h}$ at $120,000 \mathrm{~g}$ ) to remove the oxidant, whereas detergent extracts and purified cytochrome were desalted using 10DG columns (BioRad). Concentrated samples were supplemented with $18 \%$ glycerol (50\% glycerol for CG samples), transferred into EPR tubes, frozen in $\sim 1 \mathrm{~s}$ in a dry ice-ethanol mixture, and stored in liquid nitrogen. Typical cyt $b_{561}$ monomer concentrations were $25-40 \mu \mathrm{M}$ monomer for membranous preparations and 50-70 $\mu \mathrm{M}$ for isolated cytochrome.

\section{Spectroscopy}

Electronic absorption spectra were recorded with a Shimadzu Model 2101PC or a Jasco Model V-560 spectrophotometer at room temperature. EPR spectra were collected at 5-40 K with a Bruker EMX or a Varian E-6 spectrometer equipped with a liquid helium cryostat.

\section{Computer analysis}

Experimental data were analyzed using fitting routines (including the SVD algorithm) of IgorPro 5.04 (Wavemetrics, Portland, OR). Molecular graphics of the cyt $b_{561}$ structural model (3) were prepared using the software Ribbons 3.22 (54).

\section{RESULTS}

\section{The stoichiometry and EPR signals of the hemes in cyt $b_{561}$}

Cyt $b_{561}$ manifests two distinct low-spin ferric heme signals, with $g_{\mathrm{z}}$ at 3.7 and 3.1 (Fig. 1). We found the same two low-spin signals in all samples of cyt $b_{561}$ examined: in intact CG, which is a preparation intermediate between the parent chromaffin cells and purified membrane (Fig. 1, trace 1), in purified CG membranes (Fig. 1 traces 2,3) and in purified recombinant, wild type, his-tagged cyt $b_{561}$ expressed in insect cells (Fig. 1, trace 4).

In addition to the $\mathrm{g}_{\mathrm{z}} \sim 3.7$ and 3.1 signals, there is a signal from non-heme iron at $\mathrm{g}=4.3$ that is prominent in membranous samples (Fig. 1, traces 1-3) but rather insignificant in the sample of purified cytochrome (Fig. 1, trace 4 ). The small size of the signal at $g \sim 6$ establishes that 
only a very small fraction of the purified cytochrome is in the high-spin form (Fig. 1, trace 4). CG membranes prepared according to a traditional protocol (42) also exhibit a low level of high-spin species (Fig. 1, trace 3). Intact CG and Tsubaki membranes (20) have a somewhat higher content of the high-spin signal (Fig. 1, traces 1 and 2). The small signal at $g_{z}=2.84$, which is present in some of our experiments (e.g. Fig. 1, trace 4) was previously shown to derive reversibly from the $\mathrm{g}_{\mathrm{z}}=3.1$ signal in a $\mathrm{pH}$-dependent manner, possibly reflecting deprotonation of an axial histidine (40).

The $g_{z}=3.7$ and $g_{z}=3.1$ signals have been assigned to the low-potential and high-potential heme centers, respectively, based on the order in which they were reduced in titrations with ascorbate $(40,41)$. Fig 1 (inset) compares EPR spectra of fully oxidized and semi-reduced CG membranes. It is important to note that the location of the low-potential heme's EPR signal remains unchanged while its amplitudes diminishes slightly; at the same time the amplitude of the high potential heme approaches zero and no additional signals appears. This rules out a heme-heme electronic interaction in cyt $b_{561}$ (see Discussion).

Lowering the temperature of cyt $b_{561}$ from $45 \mathrm{~K}$ to $10 \mathrm{~K}$ was observed to shift the position of the high-potential peak from $\mathrm{g}=3.11$ to 3.14 without changing the position of the low-potential heme signal (41). The new signal was hypothesized to have slightly different $g$ values and significantly different relaxation properties (41). However, we suggest that the shift in peak position represents a "passage artifact"2 (55). This phenomenon is illustrated in Fig. 2, which compares the affects of microwave power on the high potential heme of cyt $b_{561}$ (Fig. 2A) and on cytochrome $c$, an undoubtedly homogeneous species at pH 7 (Fig. 2B). In both proteins, increasing the microwave power shifted the position of the peak to lower fields and caused a baseline "overshoot" at higher fields. Passage artifacts may be encountered with any low-spin hemeprotein when the spin-lattice relaxation process is overwhelmed, as occurs at high powers or very low temperatures, and is not evidence for the presence of multiple heme centers in cyt $b_{561}$ as was originally suggested (41).

\section{Global analysis of cyt $b_{561}$ absorption spectra}

We previously demonstrated that the high- and low-potential heme centers of cyt $b_{561}$ in CG membranes have unique spectral features (42). In the current experiments, we utilized purified bovine adrenal cyt $b_{561}$ expressed in yeast (20), thus improving the quality of the spectra by reducing the noise caused by light scattering and by eliminating optical interference from a minor component present in the CG membranes, a separate heme-containing protein with a low redox potential ${ }^{2}$. Fig. $3 \mathrm{~A}$ presents absolute absorption spectra of cyt $b_{561}$ recorded during titration with ascorbate. Because the midpoint potentials of the two hemes differ by $\sim 100 \mathrm{mV}$ $(36,56)$, spectral changes during the earlier stages of reduction reflect reduction of the highpotential heme exclusively. This heme has a "split" alpha band, with a pronounced maximum and a shoulder to shorter wavelength (Fig. 3B). As the titration progresses, the low-potential heme begins to contribute to the total absorbance and the spectra become somewhat more symmetric (Fig. 3A) because the alpha-band of the low-potential heme is not split and consequently has a much less contribution at shorter wavelengths (Fig. 3B).

To determine the number of spectral species necessary to explain all features of the absorption spectra at all stages of reduction, we subjected the set of 15 spectra shown in Fig. 3A to SVD analysis. Fig. 4A shows the relative amplitudes of the principal components derived from this analysis. It is clear that only SVD components 1 and 2 have significant amplitude and that the

\footnotetext{
${ }^{2}$ Passage artifacts arise when the rate of change of the total magnetic field incident on the sample is greater than the inverse of the spinlattice relaxation time. Under these conditions, the EPR signal has contributions from both absorption and dispersion modes, and distortions in the EPR spectrum result (Mailer, C., and Taylor, C. P. (1973) Rapid adiabatic passage EPR of ferricytochrome $c$ : signal enhancement and determination of the spin-lattice relaxation time. Biochim. Biophys. Acta 322, 195-203).
} 
other components can be ignored. Note that the two major SVD components (Fig. 4B) are not identical to either the spectrum of cytochrome itself or the spectra of the two heme centers shown in Fig 3B. However, using only these two components, the SVD decomposition can be reversed to reconstruct the important features of the spectra shown in Fig 3A. This is illustrated in Fig 4C, which shows experimental and calculated spectra at approximately 7, 50 and $100 \%$ reduction (corresponding to traces 1, 7 and 15 of Fig. 3A). The major features of the experimental data are reproduced so closely that the discrepancies between experimental and synthetic curves are difficult to detect (Fig. 4C). It is important to emphasize that just two SVD components are sufficient to reproduce all essential features of the cyt $b_{561}$ absorption spectra and, hence, only two spectral species contribute to the data of Fig. 3A.

\section{Expression of PAL mutant cytochromes in insect cells}

We used our established insect cell system (20) to express recombinant adrenal cyt $b_{561}$ with mutations in individual PAL residues (histidines 54, 88, 122, and 161) for EPR analysis. The insect cell expression system produced the four PAL mutants in comparable amounts, as assessed spectrophotometrically (Fig. 5). However, whereas more than $90 \%$ of the wild type cyt $b_{561}$ was extracted by detergent from insect cell membranes (20), less than $15 \%$ of the PAL mutant cytochromes were solubilized by detergent (dodecyl maltoside (with or without PMALc12), octyl glucoside, Triton X-100, CHAPS, cholate and deoxycholate were tried at a variety of detergent-to-protein ratios, with and without up to $8 \mathrm{M}$ urea). Such detergent resistance is not unique to the insect cell system or to cyt $b_{561}$. PAL mutants of cyt $b_{561}$ expressed in yeast also could not be solubilized with dodecyl maltoside (W. Liu, D. Cao, unpublished). Similar effects of PAL mutations on the extractability of the mutated protein were observed in a study of the heme $b$ subunit of succinate:quinone reductase from Bacillus subtilis (57). As the PAL mutants of cyt $b_{561}$ resisted solubilization, we proceeded with their characterization in the membrane fraction.

\section{Absorption spectra of membranous PAL mutant cytochromes}

Fig. 5A presents the reduced minus oxidized difference absorption spectrum of wild type cyt $b_{561}$ expressed in insect cell membranes. The spectrum is typical for low-spin heme $b$ containing cytochromes, with pronounced alpha, beta and gamma bands; its characteristics are quite similar to those of the CG cytochrome $(40,42)$ as well as the recombinant protein expressed in yeast $(20,21)$. Figs. 5B and 5C present the absorption spectra of PAL mutants with individual histidines substituted by glutamine, methionine or tyrosine. In addition to lowspin heme features, the spectrum of each of the mutants exhibits some high-spin characteristics (maxima at $\sim 440-450,480,625$ and $660 \mathrm{~nm}$ ), indicating that the mutations perturbed the spin state of the heme center(s).

The difference spectra from control $S f 9$ cells not infected with baculovirus or expressing an unrelated, heme-free protein, XylE, and grown with or without supplementation with ALA and heme lacked significant optical absorbance (Fig. 5B traces 5-8), showing that the host cell membranes themselves had negligible level of b-type cytochrome.

\section{Reaction of membranous PAL mutants of cyt $b_{561}$ with ascorbic acid}

Purified wild type cyt $b_{561}$ was reduced almost fully by ascorbate, the physiological reductant (Fig. 3), whereas its membranous counterpart was only $\sim 70 \%$ reduced (Fig. 6); this difference presumably reflects either changes in the cytochrome's redox potentials or decreased access to the reductant because of membrane components.

The membranous PAL mutants were much less reactive with ascorbate than the wild type cytochrome. Addition of $40 \mathrm{mM}$ ascorbate reduced the mutants at His 161 and His 88 to 30\% of the extent achieved with dithionite, as illustrated for H88Q (Fig. 6). Similar results were 
reported by Berczi et al. for His 88 and His161 (bovine cytochrome numbering) mutants of murine cyt $b_{561}$ expressed in yeast (21). Mutants of His54 and His122 were completely unreactive with ascorbate, as shown in Fig. 6 for H122Q. This difference in ascorbate reactivity between the His54/His122 and His88/His161 mutant pairs is further evidence that the optical spectra originate from recombinant cyt $b_{561}$ proteins rather than some endogenous $S f 9$ cytochrome. The different effects on ascorbate reactivity of mutations at the two heme centers perhaps reflects changes in the centers' redox potential, so that mutation of the center ligated by His 54 and His 122 causes a larger decrease in redox potential than does mutation involving the heme center ligated by His161 and His88.

\section{Effects of PAL mutations on the EPR spectrum}

EPR spectra of membranous cyt $b_{561}$ with mutated PAL are presented on Fig. 7 along with the spectra of wild type cytochrome and control membranes. In the low spin area, the familiar wild type signals with $g_{z}$ at 3.1 and 3.7 are replaced in the mutants with two new low-spin signals. The first signal has $g_{z}=2.96, g_{y}=2.26$; the second signal is characterized by $g_{z}=2.46$ and $\mathrm{g}_{\mathrm{y}}=2.26$. Similar EPR changes were observed when the targeted PAL histidine was substituted with methionine or tyrosine, which are potential axial ligands (Fig. 7A) or with glutamine, which does not ligate heme (Fig. 7B). In the broader magnetic field interval (shown in Fig. 7C for $\mathrm{H} 88 \mathrm{Q}$ ), a prominent high-spin signal at $\mathrm{g}=6.0$ and non-heme iron $\mathrm{g}=4.3$ signal are observed. A small signal at $\mathrm{g}=1.90$ is associated with $\mathrm{g}_{\mathrm{z}}=2.46$. It is notable that all PAL mutations in either heme center resulted in the appearance of the same set of heme spectral species. Control membranes from cells expressing no cyt $b_{561}$ (with or without addition of heme and ALA during culture), showed no significant EPR signals (Fig. 7B), indicating that the host cell membranes have negligible endogenous EPR-active species.

It is clear from the EPR spectra in Fig. 7A that tyrosine substitution at His54 or His161 did not result in ligation of either heme (58); methionine substituted at those positions may have become a ligand (much as reported in (57)), producing a complicated situation in which multiple new low-spin signals with slightly different g-values can be observed at high microwave power (not shown). These new signals could reflect species with slightly different relative orientations of the remaining histidine and methionine (59). In any case, the similarity of the spectra for tyrosine, methionine, and glutamine substitutions at His54 and His122 (Fig. $7 \mathrm{~A}$ and $\mathrm{B}$ ) indicate that the size and the nature of the substituted residue had little effect on the overall outcome; it was the loss of the histidine functionality as the axial ligand that was responsible for the observed effects.

With one set of PAL mutants in which glutamine was substituted for individual histidines, raising the microwave power from $1 \mathrm{~mW}$ (used for the spectra in Fig. 7) to higher levels more favorable for HALS observation (see Supporting Information) elicited a signal at $\mathrm{g}_{\mathrm{z}}=3.7 \mathrm{in}$ the H88Q and H161Q mutants (Fig. 8). This indicates that a portion of the low-potential heme center survived the general perturbation of the heme environments caused by these mutations. Importantly, HALS signals were not observed in the His54Q and His122Q mutants (Fig. 8). The HALS signals are rather small and under other circumstances might have gone unnoticed because the baselines are far from ideal. To minimize the latter problem, we subtracted the spectrum of the H54Q or the H122Q mutant from that of the H161Q mutant at each microwave power. The results (Fig. 8, lower two panels), show the appearance of the HALS signal at high powers more convincingly. The presence of the negative peak in the H161Q minus H54Q difference spectrum (Fig. 8, lower left) reflects the remarkable differences in saturation properties of the signal at $\mathrm{g} \sim 2.95$ between the H54Q and H161Q mutants. These EPR results connect the low-potential (HALS) heme center with His54 and His 122. 


\section{DISCUSSION}

\section{EPR signals of heme in wild type cyt $b_{561}$}

The experimental data in this study refute arguments that cyt $b_{561}$ is other than a two hemecontaining protein. Burbaev et al. (41) found the $\mathrm{g}_{\mathrm{z}}=3.1$ signal shifts to lower field with the lowering of temperature and interpreted this as evidence for a third heme in cyt $b_{561}$. We reproduced the earlier data in the present experiments by varying microwave power but also found that similar spectral changes could be demonstrated with cytochrome $c$ (Fig. 2B). Thus, we believe that the pseudo-heterogeneity of $\mathrm{g}_{\mathrm{z}}=3.1$ signal is best explained as an artifact that can occur at high power and/or low temperatures ${ }^{2}$.

Wanduragala et al. (43) observed that their preparation exhibited only a nominal quantity of the $\mathrm{g}_{\mathrm{z}}=3.7$ signal and raised doubts that this signal originates from a heme center in purified cyt $b_{561}$. From the power and temperature dependencies of $\mathrm{g}_{\mathrm{z}}=3.1$ and 3.7 signals (see Supporting Information) one can conclude that the quantity of low-potential heme was substantially underestimated by Wanduragala et al. (43) because the EPR conditions they employed $(20 \mathrm{~mW}$ and $15 \mathrm{~K})$ are far from optimal for observing the $\mathrm{g}_{\mathrm{z}}=3.7$ species. To address concerns similar to those raised by Wanduragala et al. (43) that isolation of cyt $b_{561}$ or even preparation of membranes from CG could cause partial denaturation and the appearance of an additional, non-native EPR signal, we recorded EPR spectra of freshly prepared CG. The resulting EPR spectrum (Fig. 1, trace 1) shows the same EPR signals of cyt $b_{561}$ that are characteristic of the purified and membranous samples of endogenous and recombinant cyt $b_{561}$, with or without a his tag $(10,20,21,40-42)$.

Kipp et al. (44) discussed the possibility that an EPR signal may be caused by electronic interactions between hemes situated on separate molecules of a cytochrome containing just one heme, thus generating the additional EPR signal which was, in their view, misinterpreted as the signal of a second heme center in cyt $b_{561}$. There are several difficulties with this proposal with the most telling being that the $\mathrm{g}_{\mathrm{z}}=3.7$ resonance should shift to a position approximately midway between the $g_{z}=3.7$ and $g_{z}=3.1$ signals in partially-reduced cytochrome, in which most of the high-potential heme is in the diamagnetic, ferrous state. There is no shift in $\mathrm{g}_{\mathrm{z}}=$ 3.7 position in the spectrum of semi-reduced protein published by Burbaev et al. (41), which we now confirm (Fig 1, inset).

Thus, our data provides persuasive evidence for the presence of only two types of heme in cyt $b_{561}$. This is consistent with the demonstration that optical changes during reduction are well reproduced using only two components (Fig 4C) and with published stoichiometry of hemeto protein close to two in the endogenous $(40)$ and recombinant $(20,22)$ cytochrome. There appears to be no further need to develop models that require other than two hemes per polypeptide of cyt $b_{561}$.

\section{Low-spin heme EPR signals in PAL mutants}

The mutations of PAL of cyt $b_{561}$ led to loss of the characteristic low-spin signals from the native high- and low-potential hemes and appearance of an intense high-spin signal at $\mathrm{g} \sim 6$, a low-spin signal with $\mathrm{g}_{\mathrm{z}}=2.96, \mathrm{~g}_{\mathrm{y}}=2.25$ and a second low-spin signal with $\mathrm{g}_{\mathrm{z}}=2.46, \mathrm{~g}_{\mathrm{y}}=$ $2.26, g_{x} \sim 1.90$ (Fig. 7). Similar low-spin signals are known from studies of other cytochromes. An EPR signal with $\mathrm{g}_{\mathrm{z}}=2.96$ was noted as a minor species in some samples of cyt $b_{561}$ (20, $21,43,60)$ and in unrelated systems with a mutated cytochrome $b$ component $(61,62)$. This signal has been identified as "relaxed" conformation of $b$-type cytochrome in which the strain on heme ligation imposed by the native protein is removed (63). The signal with $\mathrm{g}_{\mathrm{z}}=2.46$, $\mathrm{g}_{\mathrm{y}}=2.26, \mathrm{~g}_{\mathrm{x}} \sim 1.90$ resembles those of cyt P-450 (64) and P-450 mimics (65-68). These are hemeproteins where one of the axial ligands is cysteine and the other one is water, $\mathrm{OH}^{-}$, 
histidine or proline. Cyt $b_{561}$ contains only two cysteines; in the model of Bashtovyy et al. (3) these cysteines are located near the M-side heme center. If this model is accurate, Cys57 might replace His54, or Cys125 might replace His122 under the disruption caused by a PAL mutation ${ }^{4}$.

\section{Identification of axial ligands for cyt $b_{561}$ hemes}

In a simple scenario, the absorption spectra of PAL mutants should be sufficient to determine whether particular amino acid residues furnish axial ligands to the cyt $b_{561}$ hemes. With one putative axial ligand eliminated by mutation to glutamine, the affected heme should be converted to a 5- or 6-coordinated high-spin species with one axial ligand provided by the unaffected histidine and the second ligand site being either vacant or occupied by water or hydroxide. In this scenario, the second heme of cyt $b_{561}$ is unaffected by mutation and remains low-spin; the resulting absorption spectrum of the PAL mutant exhibits a combination of lowspin and high-spin features in the Soret and retains roughly half of the intensity in the alphaband where high-spin species have little contribution. The absorption spectra of PAL mutants (Fig. 5B and C) indirectly confirm the role of the targeted histidines as axial ligands because in addition to the typical low-spin peaks there are some high-spin features in the Soret region and in the near infrared that are absent in the wild type spectrum (Fig. 5A). Although the spectra of four different types of control membranes (Fig. 5B) convincingly demonstrate that endogenous hemeproteins did not interfere, it was not possible to make a firm estimate of the heme-to-protein stoichiometry for the PAL mutants in the $S f 9$ membranes $^{5}$ and thus a definitive judgment on axial ligation of cyt $b_{561}$ could not be made using optical spectra alone.

Further insights into the consequences of PAL mutations were obtained from the EPR spectra of $S f 9$ membranes expressing cyt $b_{561}$ (Fig. 7). The initial expectation was that mutation of either axial ligand to a given heme would perturb only the EPR signal of the affected heme, leaving the signal of the second heme unchanged. Instead, any substitution at any one of the four PAL histidines resulted in a similar pattern of changes in the EPR spectrum described above. The observation of global changes in the EPR spectrum of each of the mutants with affected PALs demonstrates that modification of any of them disrupts the heme environment and thus validates the models of molecular organization of cyt $b_{561}$ introduced by Esposti $e t$ $a l$. and Okuyama et al. $(35,49)$. The global effects of the PAL mutations in cyt $b_{561}$ are reminiscent of results with the cytochrome $b$ subunit of quinol:fumarate reductase from Wolinella succinogenes, where mutation of any of the four histidines predicted to be axial ligands to the hemes (69) resulted in little or no expression of the protein (70). Assignment of those histidines as axial ligands was later confirmed by crystallography (71).

Mutations of the remaining histidine residues in bovine adrenal cyt $b_{561}$ (His92, His109 and His110) produce recombinant proteins with EPR spectra generally similar to that of the wild type cytochrome (Liu, W., Rogge, C., Shinkarev, V., Tsai, A.-L, Kamensky, Y., Palmer, G., Kulmacz, R.J., in preparation). In murine cyt $b_{561}$, mutation to alanine of the histidine corresponding to His110 did not affect its absorption spectrum (21). Taken together with the

\footnotetext{
${ }^{4}$ The appearance of a P-450-like form of cyt $b_{561}$ under denaturing conditions was noted by Wanduragala et al. (Wanduragala, S., Wimalasena, D. S., Haines, D. C., Kahol, P. K., and Wimalasena, K. (2003) pH-induced alteration and oxidative destruction of heme in purified chromaffin granule cytochrome b561: implications for the oxidative stress in catecholaminergic neurons. Biochemistry 42 , 3617-3626) but they did not definitively connect the observed signal with a P-450-like center because they observed a variation in the relative amplitudes of the two components at $\mathrm{g}=2.46$ and $\mathrm{g}=2.26$, supposedly the $\mathrm{g}_{\mathrm{z}}$ and $\mathrm{g}_{\mathrm{y}}$ of the same signal. We suggest that this variation occurs because the $\mathrm{g}_{\mathrm{y}}$ of all three minor forms of cyt $b_{561}$ discussed in this paper (the $\mathrm{pH}$-dependent form with $\mathrm{g}_{\mathrm{z}}=2.84$, the species with a "relaxed" conformation $\left(\mathrm{g}_{\mathrm{z}}=2.96\right)$ and the $\mathrm{P}-450$-like species with $\mathrm{g}_{\mathrm{z}}=2.46$ ) overlap around $\mathrm{g}=2.26$ and thus make the EPR amplitude at gy sensitive to the relative amounts of these three minor forms.

5 Attempts to estimate the quantity of PAL mutant proteins in $S f 9$ cell membranes by immunoblotting did not produce satisfactory results because the PAL mutants were refractory to extraction with SDS at room temperature; heating cyt $b_{561}$ in SDS causes aggregation of the protein (L. T. Duong and Fleming, P. J. (1982) Isolation and properties of cytochrome b561 from bovine adrenal chromaffin granules. J. Biol. Chem. 257, 8561-8564).
} 
results of site-directed mutagenesis of PALs presented here, the accumulated evidence bring the earlier predictions $(35,49)$ of axial ligation of hemes in cyt $b_{561}$ past the tipping point and leaves little doubt that the heme ligation scheme in these models is correct.

\section{The concept of a structural unit containing both heme centers of cyt $\mathbf{b}_{561}$}

The EPR spectra of mutants in axial ligand residues (Figs. 7 and 8) demonstrate that signals from both heme centers in cyt $b_{561}$ are changed dramatically in response to alteration of just one, and any one, of the four axial ligands to the two hemes. To account for this behavior, we hypothesize that the two hemes and their axial ligands are linked parts of a major structural unit in cyt $b_{561}$ that we term the "kernel." Perturbation of any of the axial ligands leads to structural changes in the whole kernel, including coordination changes at both heme centers.

Three observations illustrate the global response of the kernel to modification of any of its key elements. First, the original high-potential heme signal at $g_{z}=3.1$ was not observed in any of four PAL mutants, suggesting that the high-potential heme center was fully disrupted even though its own axial ligands were not mutated. Second, although the P-450-like signal most likely originates from the M-side heme (3), with the nearby cysteine residues (Fig. 9), the signal with $\mathrm{g}_{\mathrm{z}}=2.46$ appears not only in mutants of His54 and His122 at the M-side center but also in mutants of His 88 and His 161 at the C-side center (Fig. 7). Third, in the framework of the model of Bashtovyy et al (3) it is conceivable that when His88 is mutated it can be replaced by His 92 . However, the model does not have any histidine residues that could replace His54, His122 and His161 as axial ligands. The signal of a bis-histidine ligated hemoprotein at $g$ $\sim 2.96$ observed when those histidines were replaced by glutamine (Fig. 7B) must originate from the opposite heme center, which was not directly affected by mutation and yet was partially transformed into a "relaxed" conformation (63).

The mechanism for transmitting changes in the vicinity of one heme center to the other center is unclear, but as some other cases suggesting "cooperative" behavior involving the heme centers of bis-heme $b$-type cytochromes have been reported (70,72), this interesting general phenomenon awaits an explanation.

\section{Arrangement of cyt $b_{561}$ hemes in the CG membrane}

Earlier topological analyses $(3,35,49)$ have convincingly positioned the His54/His 122 pair near the matrix (M) surface of the CG membrane and the His88/His161 pair near the membrane's cytoplasmic (C) surface (Fig. 9). The question of which heme center is high-potential and which is low-potential has not received much attention apparently because the answer was assumed to be self evident $(3,60)$. Physiological electron transfer was presumed to occur down the gradient of $\sim 100 \mathrm{mV}$ between the redox potentials of the two hemes, i.e., from a low-potential heme on the $\mathrm{C}$-face of the membrane to a high-potential heme on the M-face. However, our EPR data support the opposite topological arrangement of the two heme centers, with the lowpotential $\left(\mathrm{g}_{\mathrm{z}}=3.7\right)$ heme center on the M-side, ligated by the His54/His122 pair and the highpotential $\left(g_{z}=3.1\right)$ heme center on the C-side, ligated by the His88/His161 pair (Fig. 9). Although the issue of the "sidedness" of the hemes of cyt $b_{561}$ remains to be resolved conclusively, one interesting implication of our topological model (Fig. 9) is that physiological transmembrane electron transport, from the cytoplasm to the CG matrix, occurs against the $\sim 100 \mathrm{mV}$ gradient of the redox potentials of the two heme centers. We hypothesize that it is the inside-positive membrane potential of up to $90 \mathrm{mV}$ (Fig. 9) created by the CG membrane H-ATPase (73) that drives electrons "uphill". The role of $\Delta \Psi$ as a driving force of electron transport was discussed when cyt $b_{561}$ was thought to contain only one heme (32); in the context of our current hypothesis the suggested role of $\Delta \Psi$ becomes even more important. It is noteworthy that although transmembrane electron transport via adrenal cyt $b_{561}$ has been demonstrated in CG ghosts (74) and in reconstituted liposome systems (31,75-77), electron 
transport was only observed in the non-physiological direction, i.e., from the M-side to the Cside. We suspect that the membrane potential, absent in these reconstitution experiments, is an important factor modulating the directionality of electron transport.

\section{Supplementary Material}

Refer to Web version on PubMed Central for supplementary material.

\section{ACKNOWLEDGMENT}

We are indebted to Dr. Vladimir Shinkarev for suggesting the SVD approach and for sharing his experience in its application. We thank Dr. Gary Gerfen for discussion of "passage artifacts" in EPR spectra and Dr. Alexander Konstantinov for critical reading of the manuscript. We are very grateful to Drs. Han Asard and Tibor Pali for sharing the coordinates of their cyt $b_{561}$ computational model, to Dr. Jayashree Soman for help with molecular graphics, and to Ms. Reva Kakkar and Mr. Dazhe Cao for assistance in preparing $S f 9$ membrane samples.

\section{REFERENCES}

(1). Tsubaki M, Takeuchi F, Nakanishi N. Cytochrome b561 protein family: expanding roles and versatile transmembrane electron transfer abilities as predicted by a new classification system and protein sequence motif analyses. Biochim. Biophys. Acta 2005;1753:174-90. [PubMed: 16169296]

(2). Verelst W, Asard H. A phylogenetic study of cytochrome b561 proteins. Genome Biol 2003;4:R38. [PubMed: 12801412]

(3). Bashtovyy D, Berczi A, Asard H, Pali T. Structure prediction for the di-heme cytochrome b561 protein family. Protoplasma 2003;221:31-40. [PubMed: 12768339]

(4). Verelst W, Asard H. Analysis of an Arabidopsis thaliana protein family, structurally related to cytochromes b561 and potentially involved in catecholamine biochemistry in plants. J. Plant Physiol 2004;161:175-181. [PubMed: 15022831]

(5). Njus D, Kelley PM. The secretory-vesicle ascorbate-regenerating system: a chain of concerted H+/ e(-)-transfer reactions. Biochim. Biophys. Acta 1993;1144:235-248. [PubMed: 8399278]

(6). Klinman JP. The copper-enzyme family of dopamine beta-monooxygenase and peptidylglycine alpha-hydroxylating monooxygenase: resolving the chemical pathway for substrate hydroxylation. J. Biol. Chem 2006;281:3013-3016. [PubMed: 16301310]

(7). Ponting CP. Domain homologues of dopamine $\beta$-hydroxylase and ferric reductase: roles for iron methabolism in neurodegenerative disorders? Hum. Mol. Genet 2001;10:1853-1858. [PubMed: 11532994]

(8). Vargas JD, Herpers B, McKie AT, Gledhill S, McDonnell J, van den Heuvel M, Davies KE, Ponting CP. Stromal cell-derived receptor 2 and cytochrome b561 are functional ferric reductases. Biochim. Biophys. Acta 2003;1651:116-123. [PubMed: 14499595]

(9). Zhang DL, Su D, Berczi A, Vargas A, Asard H. An ascorbate-reducible cytochrome b561 is localized in macrophage lysosomes. Biochim. Biophys. Acta 2006;1760:1903-1913. [PubMed: 16996694]

(10). Berczi A, Su D, Asard H. An Arabidopsis cytochrome b561 with trans-membrane ferrireductase capability. FEBS Lett 2007;581:1505-1508. [PubMed: 17376442]

(11). McKie AT, Barrow D, Latunde-Dada GO, Rolfs A, Sager G, Mudaly E, Mudaly M, Richardson C, Barlow D, Bomford A, Peters TJ, Raja KB, Shirali S, Hediger MA, Farzaneh F, Simpson RJ. An iron-regulated ferric reductase associated with the absorption of dietary iron. Science 2001;291:1755-1759. [PubMed: 11230685]

(12). Gunshin H, Starr CN, Direnzo C, Fleming MD, Jin J, Greer EL, Sellers VM, Galica SM, Andrews NC. Cybrd1 (duodenal cytochrome b) is not necessary for dietary iron absorption in mice. Blood 2005;106:2879-2883. [PubMed: 15961514]

(13). Frazer DM, Wilkins SJ, Vulpe CD, Anderson GJ. The role of duodenal cytochrome b in intestinal iron absorption remains unclear. Blood 2005;106:4413. [PubMed: 16326980]author reply 4414

(14). Turi JL, Wang X, McKie AT, Nozik-Grayck E, Mamo LB, Crissman K, Piantadosi CA, Ghio AJ. Duodenal cytochrome b: a novel ferrireductase in airway epithelial cells. Am J Physiol Lung Cell Mol Physiol 2006;291:L272-280. [PubMed: 16510471] 
(15). Su D, May JM, Koury MJ, Asard H. Human erythrocyte membranes contain a cytochrome B561 that may be involved in extracellular ascorbate recycling. J Biol Chem 2006;281:39852-39859. [PubMed: 17068337]

(16). Ji L, Nishizaki M, Gao B, Burbee D, Kondo M, Kamibayashi C, Xu K, Yen N, Atkinson EN, Fang B, Lerman MI, Roth JA, Minna JD. Expression of several genes in the human chromosome 3p21.3 homozygous deletion region by an adenovirus vector results in tumor suppressor activities in vitro and in vivo. Cancer Res 2002;62:2715-2720. [PubMed: 11980673]

(17). Ohtani S, Ueda K, Jayachandran G, Xu K, Minna JD, Roth J, Ji L. Tumor suppressor 101F6 and ascorbate synergistically and selectively inhibit non-small cell lung cancer growth by caspaseindependent apoptosis and autophagy. Cancer Res 2007;67in press

(18). Apps DK. Membrane and soluble proteins of adrenal chromaffin granules. Semin. Cell. Dev. Biol 1997;8:121-131. [PubMed: 15001087]

(19). Kamensky Y, Kulmacz RJ, Palmer G. Composition of the heme centers in chromaffin granule cytochrome b(561). Ann. N. Y. Acad. Sci 2002;971:450-453. [PubMed: 12438163]

(20). Liu W, Kamensky Y, Kakkar R, Foley E, Kulmacz RJ, Palmer G. Purification and characterization of bovine adrenal cytochrome $b_{561}$ expressed in insect and yeast cell systems. Protein Expr. Purif 2005;40:429-439. [PubMed: 15766887]

(21). Berczi A, Su D, Lakshminarasimhan M, Vargas A, Asard H. Heterologous expression and sitedirected mutagenesis of an ascorbate-reducible cytochrome b561. Arch. Biochem. Biophys 2005;443:82-92. [PubMed: 16256064]

(22). Liu W, Rogge CE, Kamensky Y, Tsai AL, Kulmacz RJ. Development of a bacterial system for high yield expression of fully functional adrenal cytochrome $b_{561}$. Protein Expr Purif. 2007in press)

(23). Skotland T, Ljones T. Direct spectrophotometric detection of ascorbate free radical formed by dopamine $\beta$-monooxygenase and by ascorbate oxidase. Biochim. Biophys. Acta 1980;630:30-35. [PubMed: 7388045]

(24). Tirrell JG, Westhead EW. The uptake of ascorbic acid and dehydroascorbic acid by chromaffin granules of the adrenal medulla. Neuroscience 1979;4:181-186. [PubMed: 215938]

(25). Beers MF, Carty SE, Johnson RG, Scarpa A. H ${ }^{+}$-ATPase and catecholamine transport in chromaffin granules. Ann. N.Y. Acad. Sci 1982:116-133. [PubMed: 6220634]

(26). Levine M, Morita K, Pollard H. Enhancement of norepinephrine biosynthesis by ascorbic acid in cultured bovine chromaffin cells. J. Biol. Chem 1985;260:12942-12947. [PubMed: 3932336]

(27). Apps DK, Pryde JG, Phillips JH. Cytochrome b561 is identical with chromomembrin B, a major polypeptide of chromaffin granule membranes. Neuroscience 1980;5:2279-2287. [PubMed: 7465055]

(28). Njus, D.; Zallakian, M.; Knoth, J. The chromaffin granule: Proton-cycling in the slow lane. In: Skulachev, VP.; Hinkle, PC., editors. Chemiosmotic Proton Circuits in Biological Membranes. Addison-Wesley Publishing Company, Inc.; Reading, Massachusetts: 1981. p. 365-374.

(29). Wakefield LM, Cass AE, Radda GK. Electron transfer across the chromaffin granule membrane. Use of EPR to demonstrate reduction of intravesicular ascorbate radical by the extravesicular mitochondrial NADH:ascorbate radical oxidoreductase. J. Biol. Chem 1986;261:9746-9752. [PubMed: 3015905]

(30). Wakefield LM, Cass AE, Radda GK. Functional coupling between enzymes of the chromaffin granule membrane. J. Biol. Chem 1986;261:9739-9745. [PubMed: 3015904]

(31). Srivastava M, Duong LT, Fleming PJ. Cytochrome b561 catalyzes transmembrane electron transfer. J. Biol. Chem 1984;259:8072-8075. [PubMed: 6330096]

(32). Beers MF, Johnson RG, Scarpa A. Evidence for an ascorbate shuttle for the transfer of reducing equivalents across chromaffin granule membranes. The J. Biol. Chem 1986;261:2529-2535.

(33). Perin MS, Fried VA, Slaughter CA, Sudhof TC. The structure of cytochrome b561, a secretory vesicle-specific electron transport protein. Embo J 1988;7:2697-2703. [PubMed: 2460342]

(34). Tsubaki M, Kobayashi K, Ichise T, Takeuchi F, Tagawa S. Diethyl pyrocarbonate modification abolishes fast electron accepting ability of cytochrome b561 from ascorbate but does not influence electron donation to monodehydroascorbate radical: identification of the modification sites by mass spectrometric analysis. Biochemistry 2000;39:3276-3284. [PubMed: 10727219] 
(35). Degli Esposti M, Kamensky Yu A, Arutjunjan AM, Konstantinov AA. A model for the molecular organization of cytochrome beta-561 in chromaffin granule membranes. FEBS Lett 1989;254:7478. [PubMed: 2776888]

(36). Apps DK, Boisclair MD, Gavine FS, Pettigrew GW. Unusual redox behaviour of cytochrome b-561 from bovine chromaffin granule membranes. Biochim. Biophys. Acta 1984;764:8-16. [PubMed: 6696883]

(37). Silsand T, Flatmark T. Purification of cytochrome $b_{561}$. An integral heme protein of the adrenal chromaffin granule membrane. Biochim. Biophys. Acta 1974;395:257-266. [PubMed: 4853975]

(38). Duong LT, Fleming PJ. Isolation and properties of cytochrome b561 from bovine adrenal chromaffin granules. J. Biol. Chem 1982;257:8561-8564. [PubMed: 7096323]

(39). Wakefield LM, Cass AE, Radda GK. Isolation of a membrane protein by chromatofocusing: cytochrome b-561 of the adrenal chromaffin granule. J. Biochem. Biophys. Meth 1984;9:331-341. [PubMed: 6491155]

(40). Tsubaki M, Nakayama M, Okuyama E, Ichikawa Y, Hori H. Existence of two heme B centers in cytochrome b561 from bovine adrenal chromaffin vesicles as revealed by a new purification procedure and EPR spectroscopy. J. Biol. Chem 1997;272:23206-23210. [PubMed: 9287327]

(41). Burbaev D, Moroz IA, Kamenskiy YA, A KA. Several forms of chromaffin granule cytochrome $b_{561}$ revealed by EPR spectroscopy. FEBS Lett 1991;283:97-99. [PubMed: 1645301]

(42). Kamensky YA, Palmer G. Chromaffin granule membranes contain at least three heme centers: direct evidence from EPR and absorption spectroscopy. FEBS Lett 2001;491:119-122. [PubMed: 11226432]

(43). Wanduragala S, Wimalasena DS, Haines DC, Kahol PK, Wimalasena K. pH-induced alteration and oxidative destruction of heme in purified chromaffin granule cytochrome $b(561)$ : implications for the oxidative stress in catecholaminergic neurons. Biochemistry 2003;42:3617-3626. [PubMed: 12653566]

(44). Kipp BH, Kelley PM, Njus D. Evidence for an essential histidine residue in the ascorbate-binding site of cytochrome b561. Biochemistry 2001;40:3931-3937. [PubMed: 11300772]

(45). Kamensky YA, Arutjunjan AM, Ksenzenko MY, Chertkova EI, Konstantinov AA. Axial ligands of haem iron in chromaffin granule cytochrome $b_{561}$. Biol. Membr. (USSR) 1990;4:667-671.

(46). Eaton WA, Hochstrasser RM. Electronic spectrum of single crystals of ferricytochrome $c$. J. Chem. Phys 1967;46:2533-2539. [PubMed: 6039380]

(47). Myer YP, Bullock PA. Cytochrome $b_{562}$ from E. coli: Conformational, configurational, and spinstate characterization. Biochemistry 1978;17:3723-3729. [PubMed: 359043]

(48). Arutyunyan AM, Sharonov YA. Fine structure of the magnetooptical rotatory dispersion curves and the surroundings of heme in ferrocytochrome $\mathrm{c}$ and its model compounds. Mol Biol (Moscow) 1974;7:478-484.

(49). Okuyama E, Yamamoto R, Ichikawa Y, Tsubaki M. Structural basis for the electron transfer across the chromaffin vesicle membranes catalyzed by cytochrome b561: analyses of cDNA nucleotide sequences and visible absorption spectra. Biochim. Biophys. Acta 1998;1383:269-278. [PubMed: 9602148]

(50). Palmer, G. Electron paramagnetic resonance of metalloproteins. In: Que, L., editor. Physical Methods in Bioinorganic Chemistry. University Science Books; Sausalito, CA: 2000. p. 121-186.

(51). Rogge CE, Liu W, Wu G, Wang LH, Kulmacz RJ, Tsai AL. Identification of Tyr504 as an alternative tyrosyl radical site in human prostaglandin H synthase-2. Biochemistry 2004;43:1560-1568. [PubMed: 14769032]

(52). Berry EA, Trumpower BL. Simultaneous determination of hemes a, b, and c from pyridine hemochrome spectra. Anal Biochem 1987;161:1-15. [PubMed: 3578775]

(53). Falk, J. Porphyrins and Metalloporphyrins. Elsevier; Amsterdam: 1964.

(54). Carson, M. Methods Enzymol. 1997. Ribbons; p. 493-505.

(55). Mailer C, Taylor CP. Rapid adiabatic passage EPR of ferricytochrome c: signal enhancement and determination of the spin-lattice relaxation time. Biochim. Biophys. Acta 1973;322:195-203. [PubMed: 4358082] 
(56). Takeuchi F, Kobayashi K, Tagawa S, Tsubaki M. Ascorbate inhibits the carbethoxylation of two histidyl and one tyrosyl residues indispensable for the transmembrane electron transfer reaction of cytochrome b561. Biochemistry 2001;40:4067-4076. [PubMed: 11300787]

(57). Matsson M, Tolstoy D, Aasa R, Hederstedt L. The distal heme center in Bacillus subtilis succinate:quinone reductase is crucial for electron transfer to menaquinone. Biochemistry 2000;39:8617-8624. [PubMed: 10913269]

(58). Tsai AL, Kulmacz RJ, Wang JS, Wang Y, Van Wart HE, Palmer G. Heme coordination of prostaglandin H synthase. J. Biol. Chem 1993;268:8554-8563. [PubMed: 8386163]

(59). Brautigan DL, Feinberg BA, Hoffman BM, Margoliash E, Peisach J, Blumberg WE. Multiple low spin forms of the cytochrome $\mathrm{c}$ ferrihemochrome. EPR spectra of various eukaryotic and prokaryotic cytochromes c. J Biol Chem 1977;252:574-582. [PubMed: 13072]

(60). Takeuchi F, Hori H, Tsubaki M. Selective Perturbation of the Intravesicular Heme Center of Cytochrome b561 by Cysteinyl Modification with 4,4'-Dithiodipyridine. J. Biochem. (Tokyo) 2005;138:751-562. [PubMed: 16428304]

(61). Magalon A, Lemesle-Meunier D, Rothery RA, Frixon C, Weiner JH, Blasco F. Heme axial ligation by the highly conserved His residues in helix II of cytochrome b (NarI) of Escherichia coli nitrate reductase A. J Biol Chem 1997;272:25652-25658. [PubMed: 9325288]

(62). Crouse BR, Yu CA, Yu L, Johnson MK. Spectroscopic identification of the axial ligands of cytochrome b560 in bovine heart succinate-ubiquinone reductase. FEBS Lett 1995;367:1-4. [PubMed: 7601275]

(63). Salerno JC, Leigh JS. Crystal field of atypical low-spin ferriheme complexes. J. Am. Chem. Soc 1984;106:2156-2159.

(64). Tsai R, Yu CA, Gunsalus IC, Peisach J, Blumberg W, Orme-Johnson WH, Beinert H. Spin-state changes in cytochrome P-450cam on binding of specific substrates. Proc. Natl. Acad. Sci. U S A 1970;66:1157-1163. [PubMed: 4319883]

(65). Hildebrand DP, Ferrer JC, Tang HL, Smith M, Mauk AG. Trans effects on cysteine ligation in the proximal His93Cys variant of horse heart myoglobin. Biochemistry 1995;34:11598-11605. [PubMed: 7547891]

(66). Sigman JA, Pond AE, Dawson JH, Lu Y. Engineering cytochrome c peroxidase into cytochrome P450: a proximal effect on heme-thiolate ligation. Biochemistry 1999;38:11122-11129. [PubMed: 10460168]

(67). Smulevich G, Bjerrum MJ, Gray HB, Spiro TG. Resonance Raman spectra and the active site structure of semisynthetic Met80Cys horse heart cytochrome c. Inorganic Chemistry 1994;33:4629-4634.

(68). Lanzilotta WN, Schuller DJ, Thorsteinsson MV, Kerby RL, Roberts GP, Poulos TL. Structure of the CO sensing transcription activator CooA. Nat Struct Biol 2000;7:876-880. [PubMed: 11017196]

(69). Kortner C, Lauterbach F, Tripier D, Unden G, Kroger A. Wolinella succinogenes fumarate reductase contains a dihaem cytochrome b. Mol Microbiol 1990;4:855-860. [PubMed: 2388563]

(70). Simon J, Gross R, Ringel M, Schmidt E, Kroger A. Deletion and site-directed mutagenesis of the Wolinella succinogenes fumarate reductase operon. Eur. J. Biochem 1998;251:418-426. [PubMed: 9492313]

(71). Lancaster CR, Kroger A. Succinate: quinone oxidoreductases: new insights from X-ray crystal structures. Biochim Biophys Acta 2000;1459:422-431. [PubMed: 11004459]

(72). Finegold AA, Shatwell KP, Segal AW, Klausner RD, Dancis A. Intramembrane bis-heme motif for transmembrane electron transport conserved in a yeast iron reductase and the human NADPH oxidase. J Biol Chem 1996;271:31021-31024. [PubMed: 8940093]

(73). Johnson RG, Carty SE, Scarpa A. Proton: substrate stoichiometries during active transport of biogenic amines in chromaffin ghosts. J. Biol. Chem 1981;256:5773-5780. [PubMed: 7240171]

(74). Njus D, Knoth J, Cook C, Kelley PM. Electron transfer across the chromaffin granule membrane. J. Biol. Chem 1983;258:27-30. [PubMed: 6294100]

(75). Russell JT, Levine M, Njus D. Electron transfer across posterior pituitary neurosecretory vesicle membranes. J Biol. Chem 1985;260:226-231. [PubMed: 2981205] 
(76). Kent UM, Fleming PJ. Purified cytochrome b561 catalyzes transmembrane electron transfer for dopamine beta-hydroxylase and peptidyl glycine alpha-amidating monooxygenase activities in reconstituted systems. J. Biol. Chem 1987;262:8174-8178. [PubMed: 3597367]

(77). Seike Y, Takeuchi F, Tsubaki M. Reversely-oriented cytochrome b561 in reconstituted vesicles catalyzes transmembrane electron transfer and supports extravesicular dopamine beta-hydroxylase activity. J Biochem. (Tokyo) 2003;134:859-867. [PubMed: 14769875] 


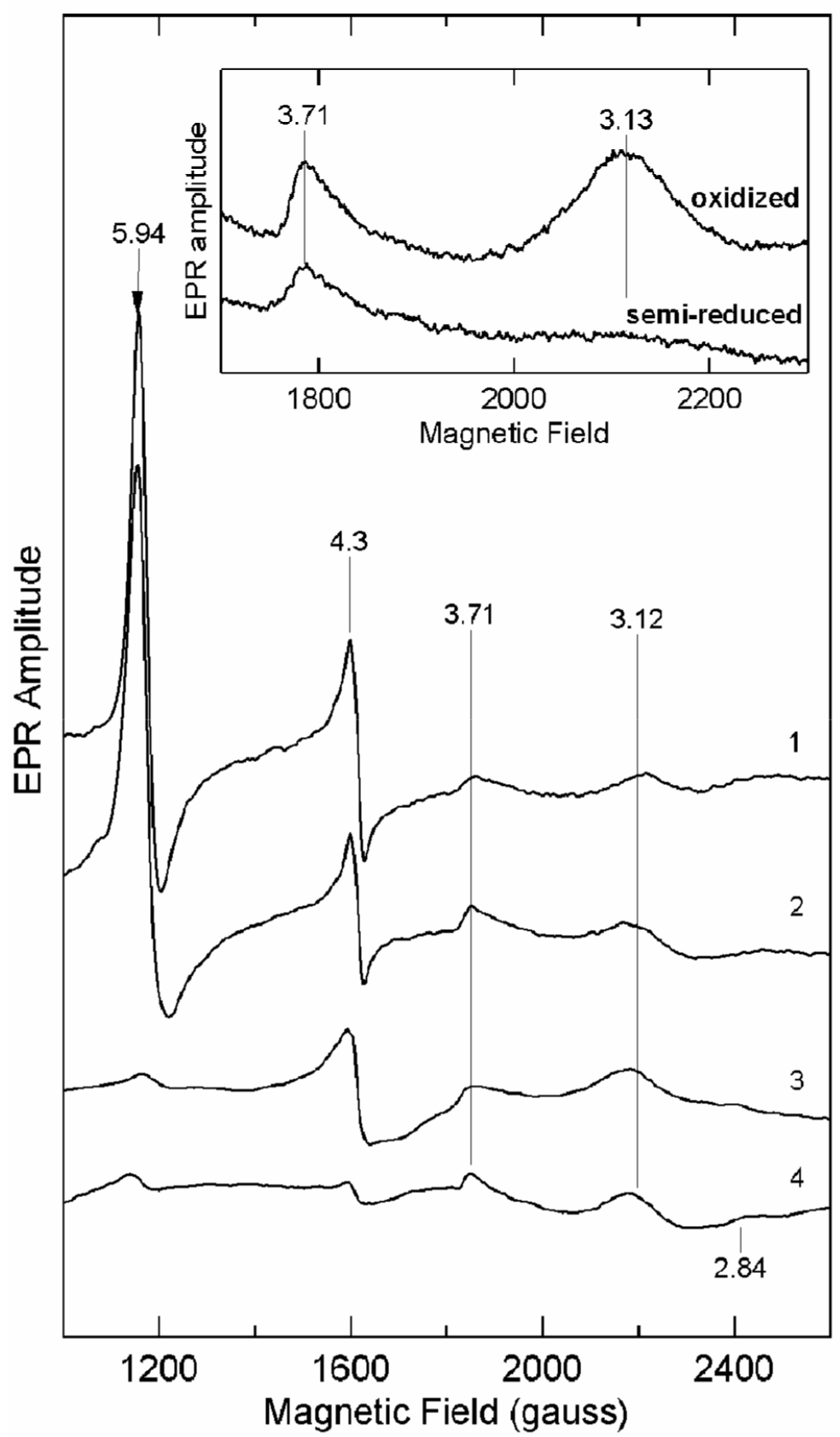

Figure 1.

EPR signals of cyt $b_{561}$ hemes in native CG, CG membranes and the purified cytochrome. EPR spectra were recorded for freshly prepared CG (trace 1), "Tsubaki membranes" (trace 2), traditionally prepared CG membranes (trace 3), and purified His-tagged cyt $b_{561}$ expressed in Sf9 cells (trace 4). Signal amplitudes were normalized to the heme concentration. Membranous samples (traces 1-3) were suspended in $20 \mathrm{mM}$ Tris, pH 7.2, with $18 \%$ glycerol, except for freshly prepared CG, where the glycerol concentration was 50\%. Purified cytochrome sample (trace 4) was in $100 \mathrm{mM}$ sodium phosphate, $\mathrm{pH} 7.2$, containing $18 \%$ glycerol and $1 \%$ octyl glucoside. The microwave power and temperatures were: $1,15 \mathrm{~mW} / 11 \mathrm{~K} ; 2,32 \mathrm{~mW} / 11 \mathrm{~K} ; 3$, $50 \mathrm{~mW} / 11 \mathrm{~K}$ and 4, $15 \mathrm{~mW} / 8 \mathrm{~K}$. Other spectrometer settings were: microwave frequency, 9.60 
$\mathrm{GHz}$; modulation frequency, $100 \mathrm{KHz}$; modulation amplitude, $10 \mathrm{G}$ except for trace 3 (20 G). Inset: EPR signals for oxidized and semi-reduced cyt $b_{561}$ hemes in CG membranes. Traditionally prepared CG membranes were suspended in $50 \mathrm{mM}$ Hepes, $\mathrm{pH} 7.2,0.1 \mathrm{mM}$ EDTA with $18 \%$ glycerol and either oxidized with ferricyanide (upper) or $50 \%$ reduced with ascorbate (lower) before spectra were recorded at $11.5 \mathrm{~K}$ with a microwave power of $50 \mathrm{~mW}$. Other spectrometer settings were: microwave frequency, $9.27 \mathrm{GHz}$; modulation frequency, $100 \mathrm{KHz}$; modulation amplitude, $20 \mathrm{G}$. 


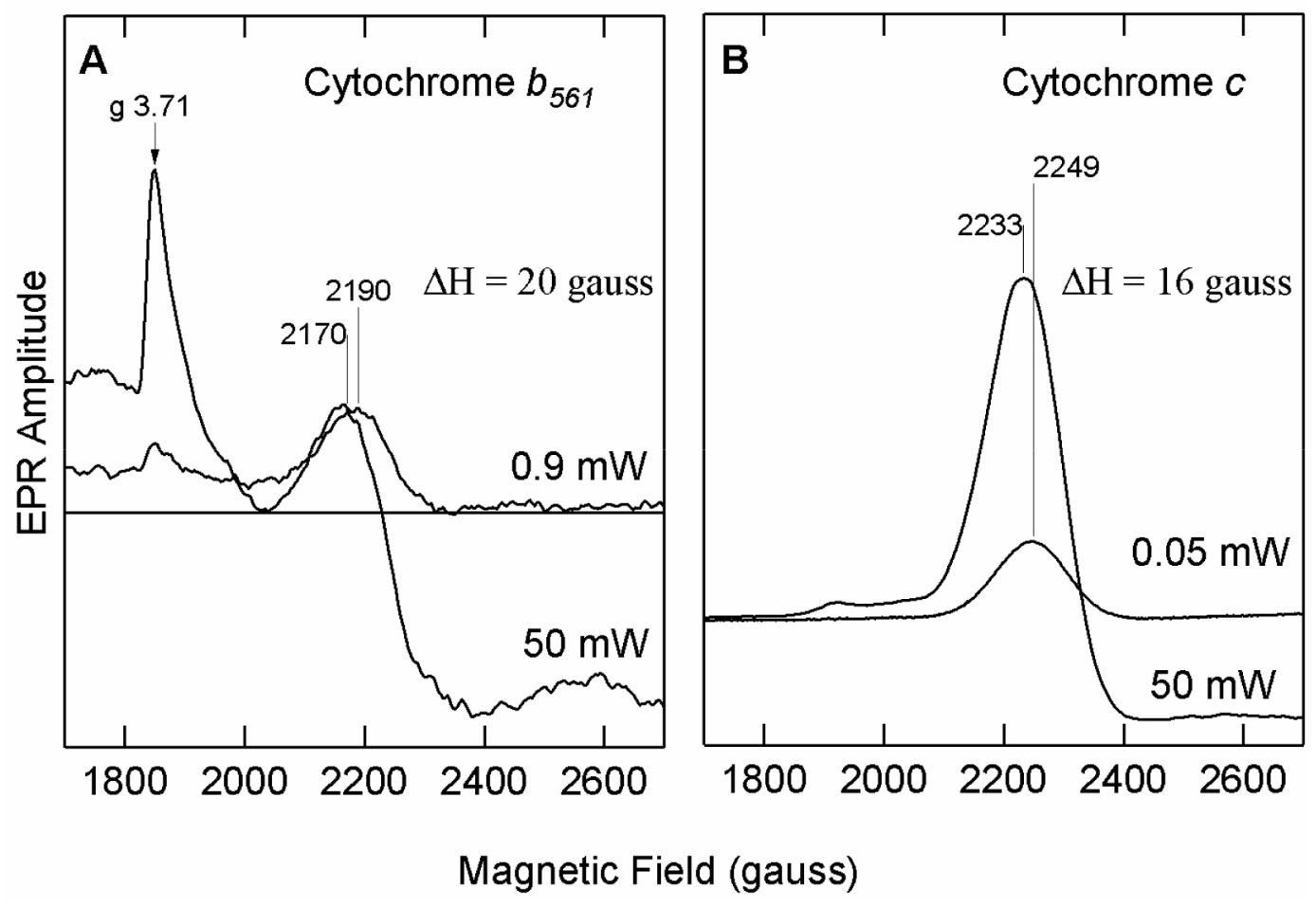

Figure 2.

Effects of microwave power on the EPR signal of the high-potential heme of cyt $b_{561}$. A: The EPR spectrum of $31 \mu \mathrm{M}$ purified cyt $b_{561}$ from $C G$ membranes in $50 \mathrm{mM}$ sodium phosphate, pH 7.3, containing $18 \%$ glycerol and $1 \%$ octyl glucoside was recorded at 0.9 and $50 \mathrm{~mW}$. B: the EPR spectrum of $200 \mu \mathrm{M}$ horse heart cytochrome $\mathrm{c}$ in $60 \mathrm{mM}$ sodium phosphate, $\mathrm{pH} 6.8$, containing $20 \%$ glycerol was recorded at 0.05 and $128 \mathrm{~mW}$. Spectrometer conditions: microwave frequency, $9.60 \mathrm{GHz}$; modulation frequency, $100 \mathrm{KHz}$; modulation amplitude, 10 $\mathrm{G}$; and temperature, $8.0 \mathrm{~K}$. 

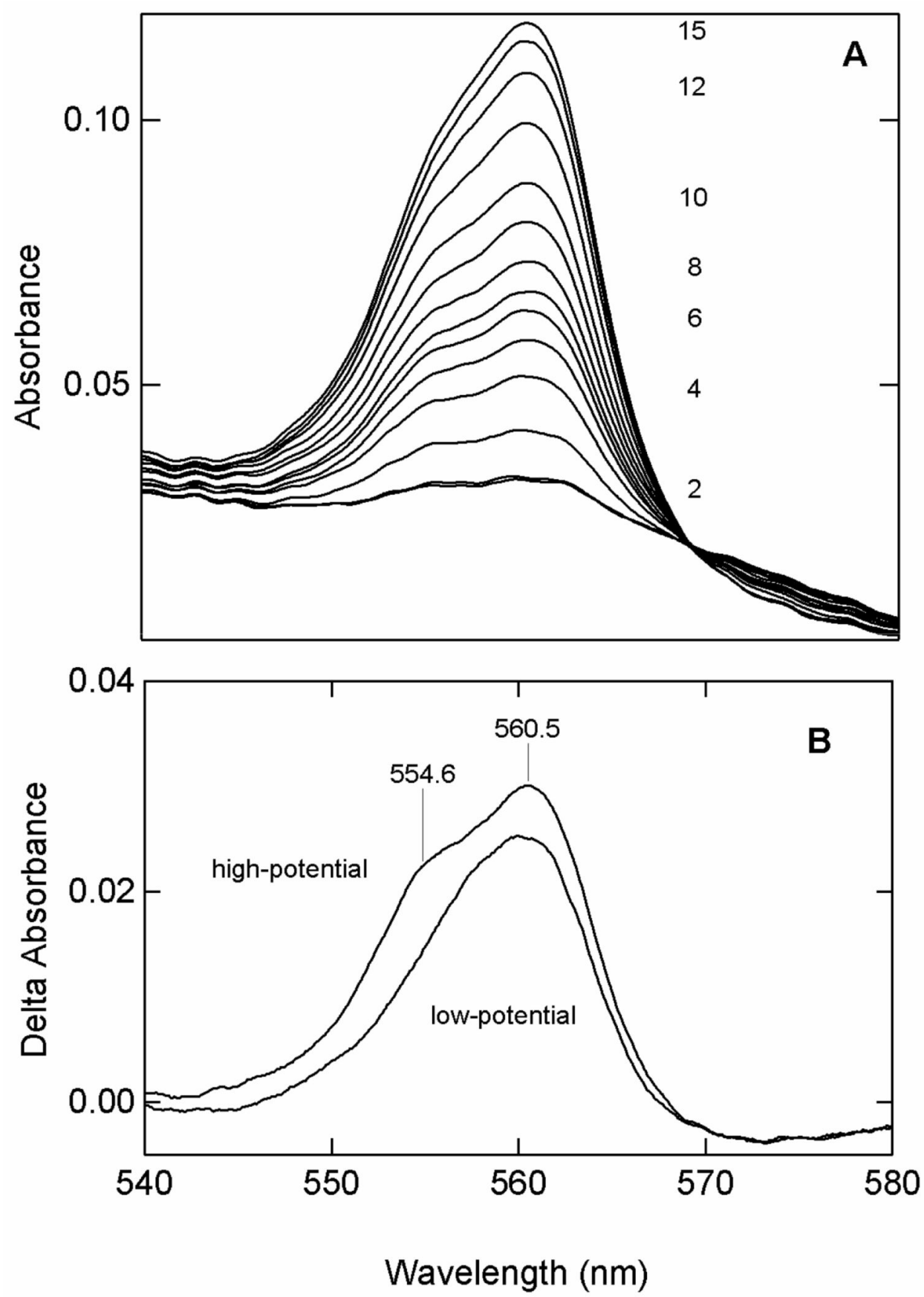

Figure 3.

Absorption spectra of the high- and low-potential hemes of cyt $b_{561}$. A: Absolute spectra of cyt $b_{561}$ recorded during reductive titration with ascorbate. The purified cytochrome expressed in yeast (20) was diluted to $2.6 \mu \mathrm{M}$ in $100 \mathrm{mM}$ potassium phosphate, $\mathrm{pH} 7.2$, containing $10 \%$ glycerol and $0.08 \%$ DM. Spectra were recorded after addition of the following concentrations of ascorbate: 1, 0.3 $\mu \mathrm{M} ; 2,1.2 \mu \mathrm{M} ; 3,5.2 \mu \mathrm{M} ; 4,12.3 \mu \mathrm{M} ; 5,22.4 \mu \mathrm{M} ; 6,35.5 \mu \mathrm{M} ; 7,52 \mu \mathrm{M}$; 8, $71 \mu \mathrm{M} ; 9,105 \mu \mathrm{M} ; 10,170 \mu \mathrm{M} ; 11,0.53 \mathrm{mM} ; 12,1.2 \mathrm{mM} ; 13,8.5 \mathrm{mM}$; and 14 (not shown for clarity), $19.6 \mathrm{mM}$. Trace 15 was recorded after addition of a few crystals of dithionite. Spectra were collected at $0.1 \mathrm{~nm}$ intervals with a $1.0 \mathrm{~nm}$ bandwidth and a scanning speed of $20 \mathrm{~nm} / \mathrm{min}$. B: Difference spectra of individual heme centers calculated from spectra in panel 
A. High potential heme, trace 6 minus trace 2; low potential heme, trace 12 minus trace 9 . Note that the spectra in $3 \mathrm{~B}$ represent the shape of each component, not their relative amplitudes. 

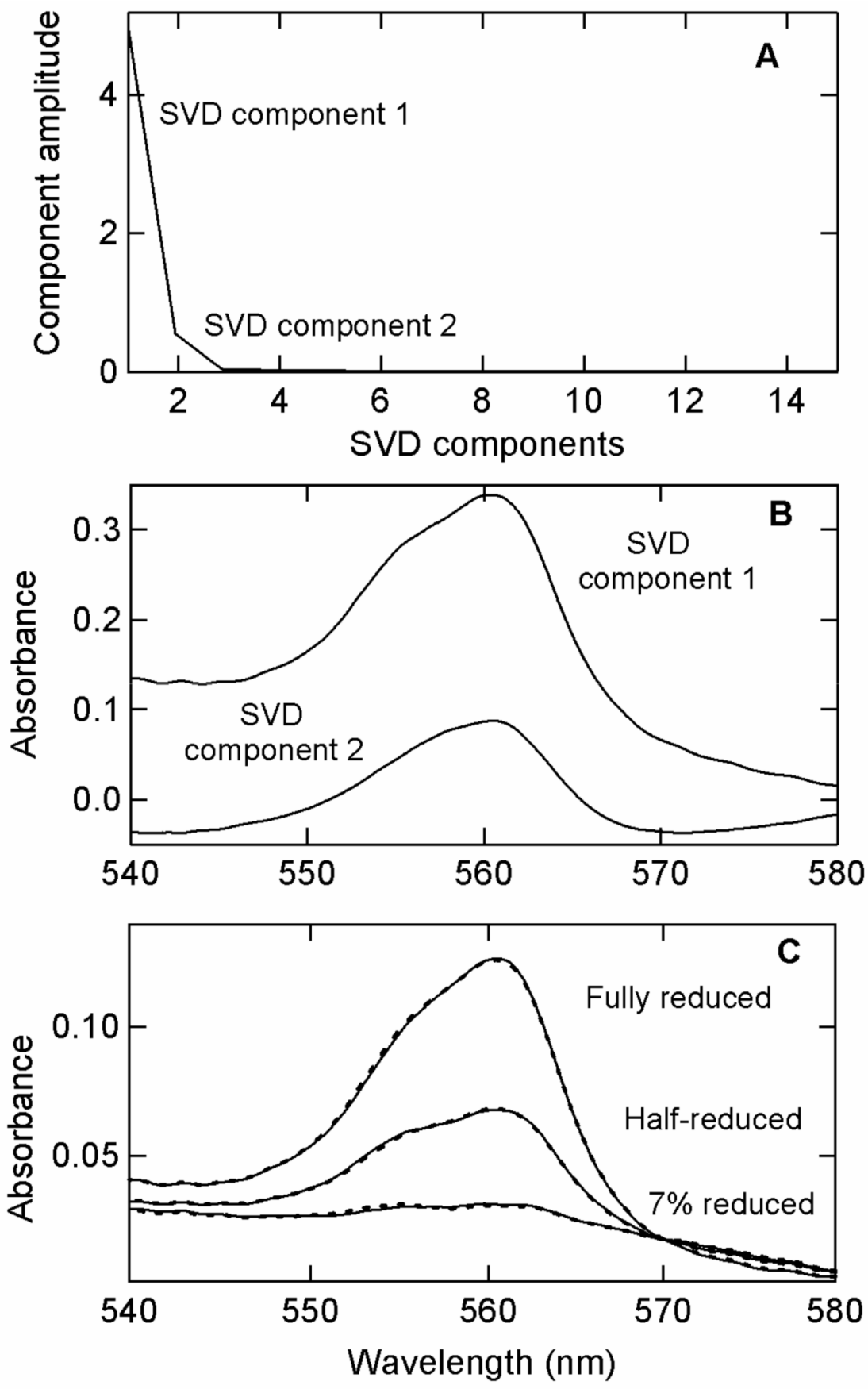

Figure 4.

SVD analysis of absorption spectra of wild type cyt $b_{561}$ during reductive titration with ascorbate. A: Relative amplitudes of the principal components derived from SVD analysis of the spectra shown in Fig. 3A. B: Spectra of the two major components in panel A. C: Reconstruction of the $7 \%$ reduced, half-reduced and fully reduced spectra from Fig. 3A (traces 1,7 and 15, respectively). The solid lines represent the original experimental data and the dashed lines represent the reconstructed spectra using only principal components 1 and 2 from panel B. 

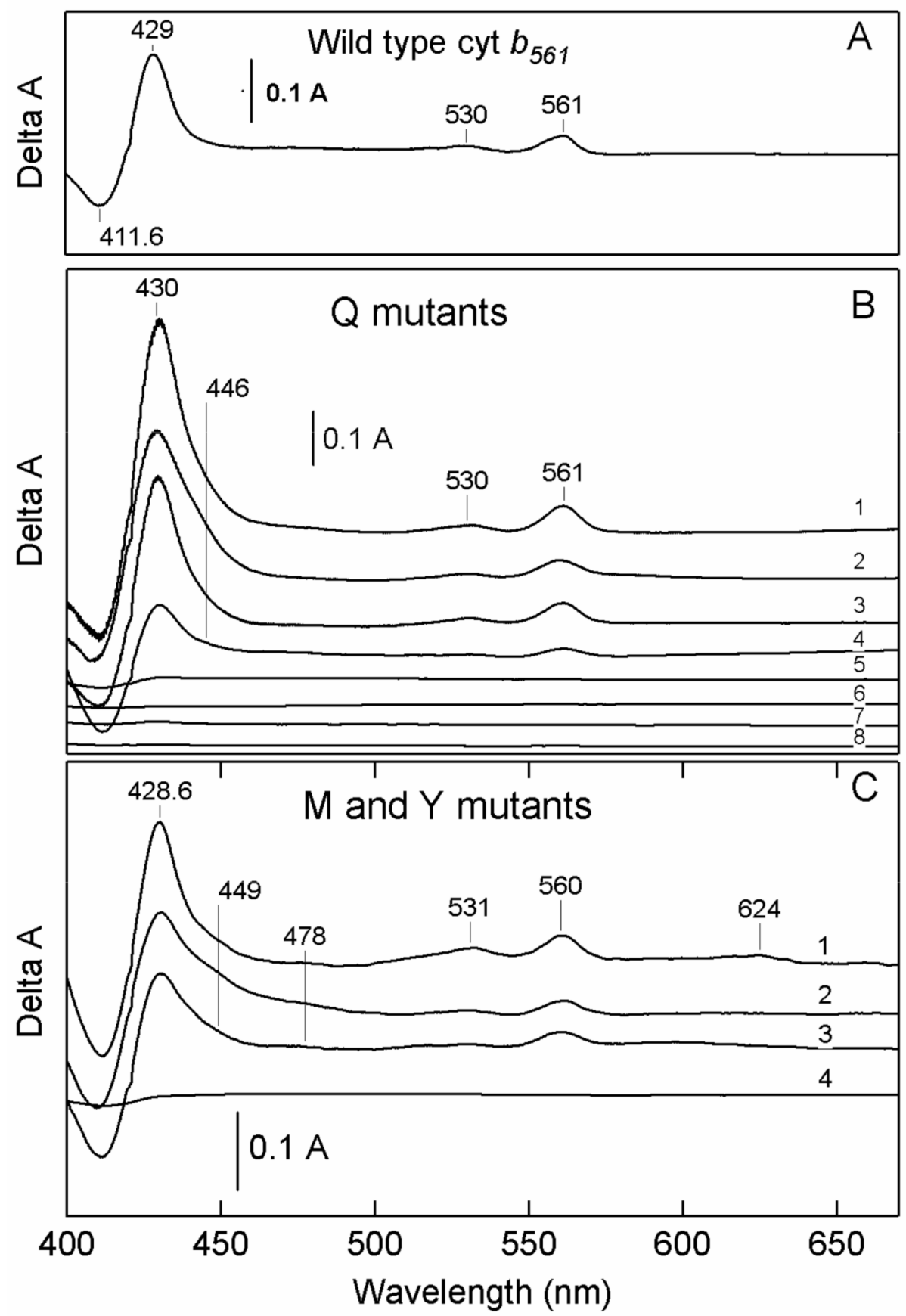

Figure 5.

Reduced minus oxidized difference absorption spectra of wild type and mutant cyt $b_{561}$ in Sf9 cell membranes. A: Wild type cyt $b_{561}$. B: 1, H161Q; 2, H122Q; 3, H88Q; 4, H54Q; 5, membranes from cells expressing XylE and supplemented with ALA and hemin; 6, membranes from unsupplemented cells expressing XylE; 7, membranes from uninfected cells supplemented with ALA and hemin; and 8, membranes from unsupplemented, uninfected cells. C: 1, H161Y; 2, H161M; 3, H54Y; and 4, membranes from cells expressing XylE and supplemented with ALA and hemin. All membrane samples were suspended in $60 \mathrm{mM}$ Tris, $\mathrm{pH} 7.4$, containing $20 \%$ glycerol and were reduced with a few grains of dithionite. The absolute absorption spectra were collected at $0.2 \mathrm{~nm}$ intervals with a $0.1 \mathrm{~nm}$ bandwidth and a scanning 
speed of $200 \mathrm{~nm} / \mathrm{min}$; difference spectra were produced by subtraction of oxidized from reduced spectra and their amplitudes normalized for total membrane protein and for the relative level of wild type cytochrome expression in the corresponding batch of $S f 9$ cells. 


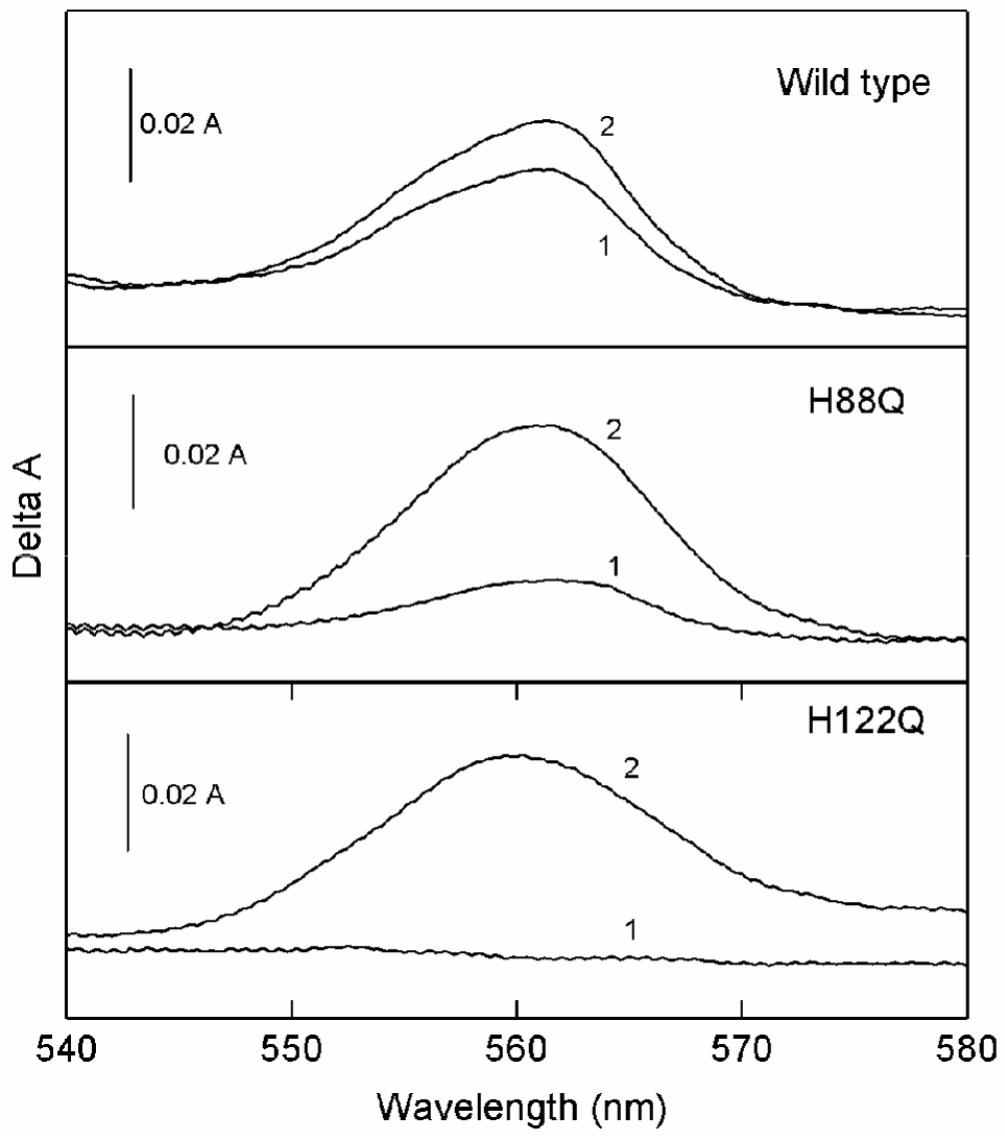

Figure 6.

Difference optical spectra of $S f 9$ cell membranes containing recombinant wild type cyt $b_{561}$ and two PAL mutants after reaction with ascorbate (1) and dithionite (2). Membrane

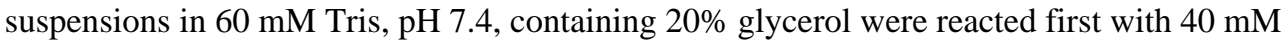
ascorbate and subsequently with a few grains of dithionite. Absolute absorption spectra were collected for oxidized and reductant-treated samples at $0.1 \mathrm{~nm}$ intervals with a $0.05 \mathrm{~nm}$ bandwidth and a scanning speed of $40 \mathrm{~nm} / \mathrm{min}$. Reduced minus oxidized difference absorption spectra were calculated and normalized to a protein concentration of $1 \mathrm{mg} / \mathrm{ml}$. 

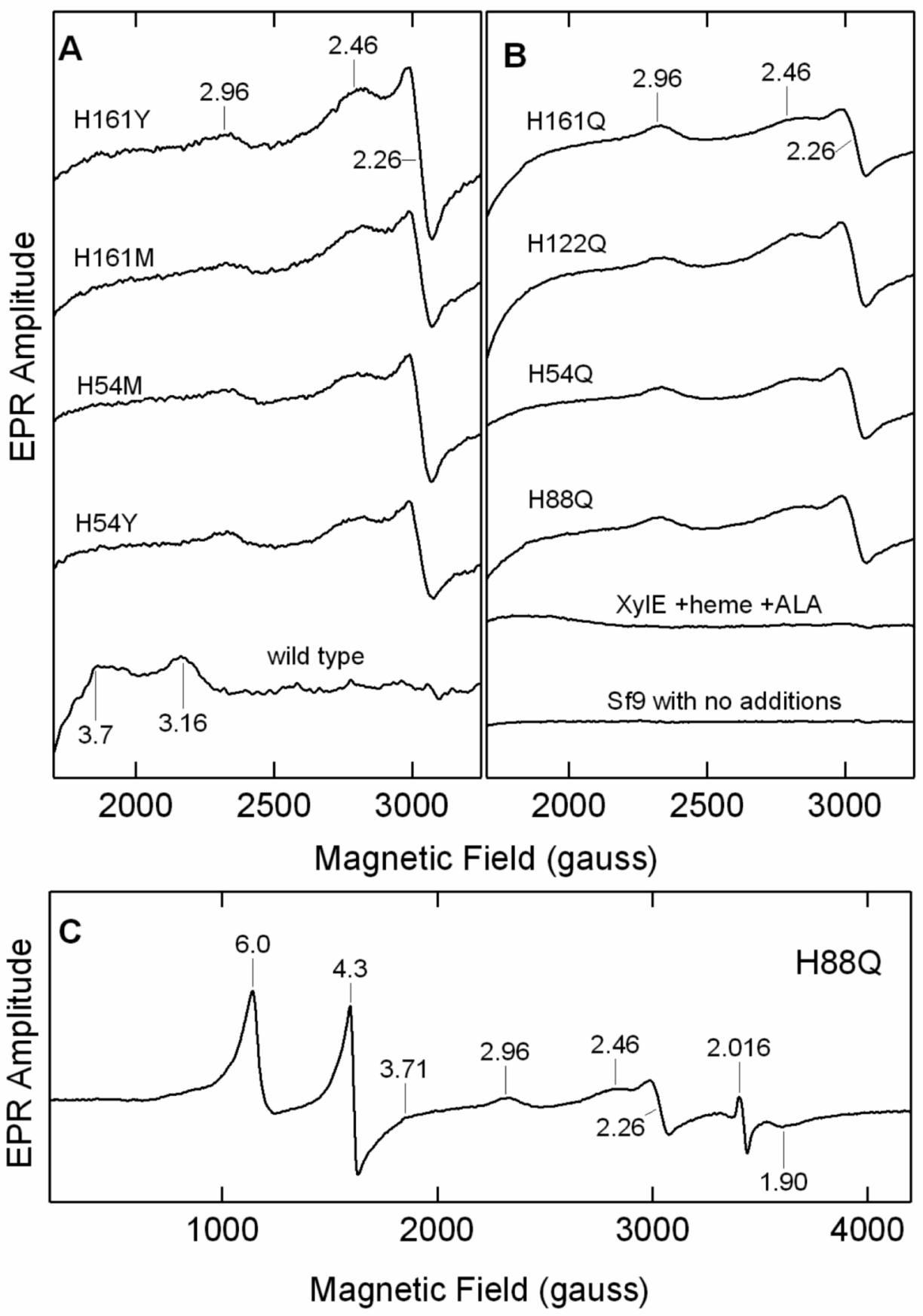

Figure 7.

EPR spectra of PAL mutants of cyt $b_{561}$ in $S f 9$ cell membranes. A and B: Low-spin region of the EPR spectra of $S f 9$ cell membranes containing recombinant wild type cyt $b_{561}$ and mutants with PAL histidines replaced by methionine or tyrosine (A) or glutamine (B). The spectra of membranes from Sf9 cells expressing XylE and supplemented with ALA and hemin, and membranes from unsupplemented, uninfected $S f 9$ cells are presented in panel B as controls. C: Wide-scan EPR spectrum of $S f 9$ cell membranes containing the H88Q mutant. Membranes were suspended in $20 \mathrm{mM}$ Tris, $\mathrm{pH} 7.2$, and containing $20 \%$ glycerol. Signal intensities are normalized for total protein concentration and for the relative level of wild type cytochrome expression in the corresponding batch of $S f 9$ cells. Spectrometer conditions: microwave 
frequency, $9.60 \mathrm{GHz}$; microwave power, $1 \mathrm{~mW}$; modulation frequency, $100 \mathrm{KHz}$; modulation amplitude, $10 \mathrm{G}$; and temperature, $8 \mathrm{~K}$. 

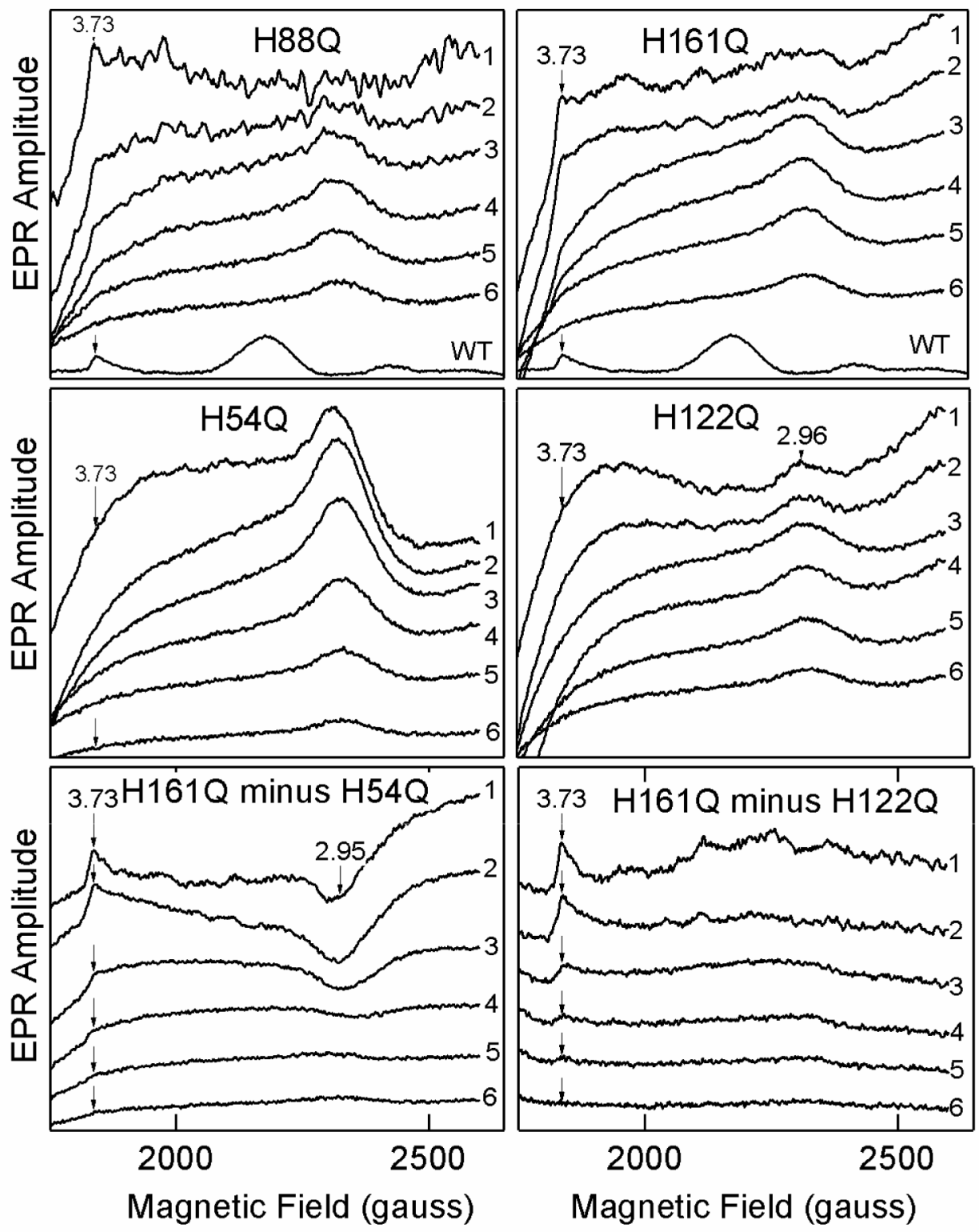

Figure 8.

Effects of microwave power on EPR spectra of $S f 9$ cell membranes containing glutaminesubstituted PAL mutants of cyt $b_{561}$. The spectra were recorded at 200 (1), 50 (2), 12.8 (3) 3.2 (4), 0.8 (5) or $0.2 \mathrm{~mW}(6)$. Signal intensities were normalized for total protein concentration in the individual samples. Spectrometer conditions were: microwave frequency, $9.60 \mathrm{GHz}$; modulation frequency, $100 \mathrm{KHz}$; modulation amplitude, $10 \mathrm{G}$; and the temperature, $8 \mathrm{~K}$. The two lowest panels represent difference EPR spectra derived from the upper panels as indicated. The spectrum of purified wild type (WT) cytochrome expressed in $S f 9$ cells (collected at 4 $\mathrm{mW}$ ) is shown in the two upper panels for comparison. 


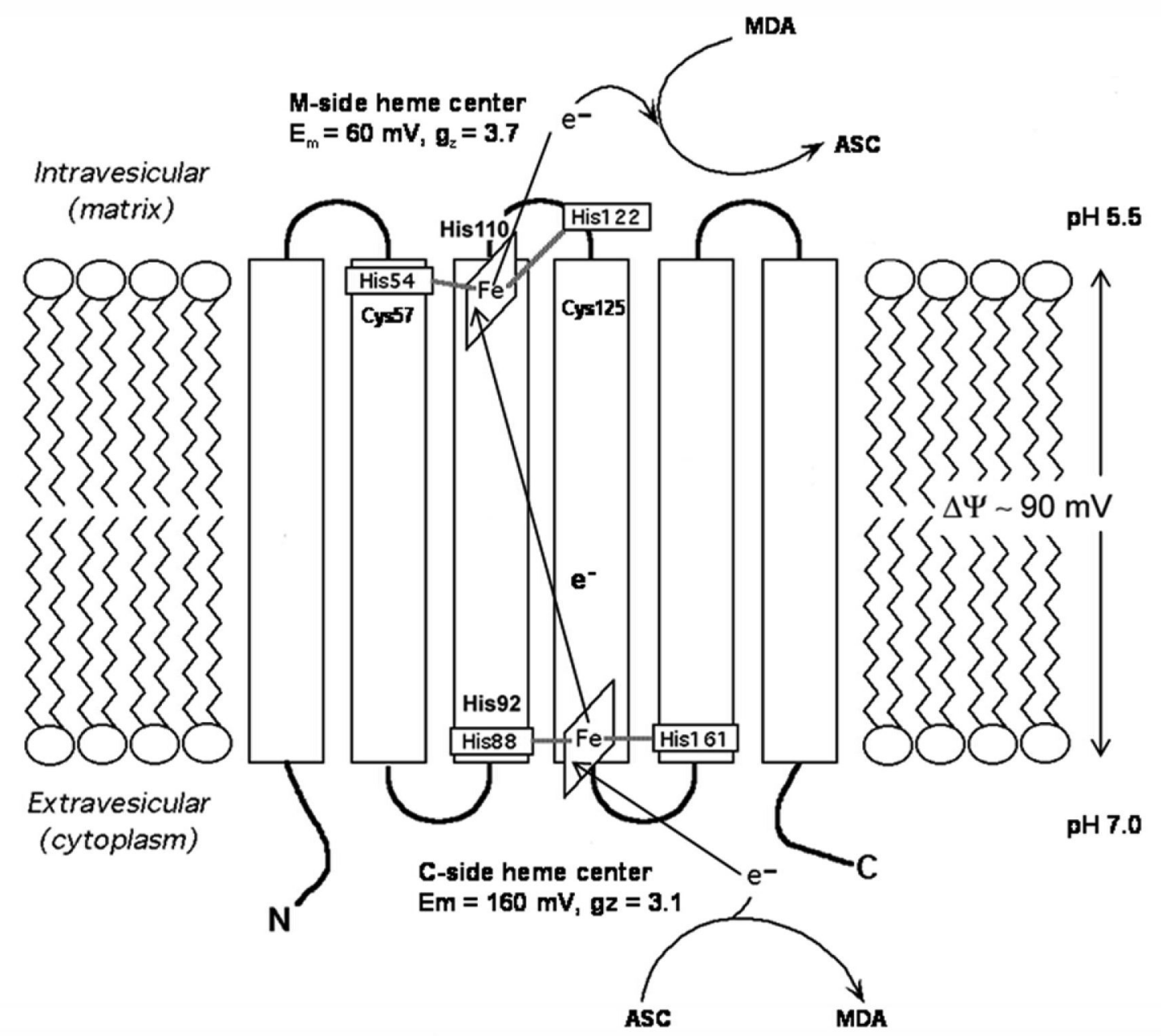

Figure 9.

Topological model of adrenal cyt $b_{561}$ in the CG membrane. The axial ligation of heme centers is based on proposals by Degli Esposti et al. (35) and Okuyama et al. (49) and on the results of the present study. The disposition of the low-potential heme on the M-side and the highpotential heme on the $\mathrm{C}$-side of the membrane is justified in the text. According to the current paradigm, cytoplasmic ascorbate is oxidized to MDA by cyt $b_{561}$, which shuttles electrons across the membrane and reduces MDA in the matrix. The $\mathrm{V}_{1} \mathrm{~V}_{0}$ type $\mathrm{H}^{+}$-ATPase (not shown) maintains a transmembrane $\mathrm{H}^{+}$-electrochemical gradient. Its membrane potential component, $\Delta \Psi$ may be important for driving electrons against the gradient of the redox potentials of two hemes of the cytochrome, as discussed in the text. Histidines 122, 54, 161, 88, marked with boxes, are putative axial ligands to the hemes. ASC, ascorbate; MDA, monodehydroascorbate; $\Delta \Psi$, membrane potential. 